\title{
Pseudorabies Virus Infection of the Rat Central Nervous System: Ultrastructural Characterization of Viral Replication, Transport, and Pathogenesis
}

\author{
J. P. Card, ${ }^{1}$ L. Rinaman, ${ }^{2, a}$ R. B. Lynn, ${ }^{3}$ B.-H. Lee, ${ }^{4}$ R. P. Meade, ${ }^{1}$ R. R. Miselis, ${ }^{5}$ and L. W. Enquist' \\ 'Viral Diseases Research, Du Pont Merck Pharmaceutical Co., Wilmington, Delaware 19880, 2 Medical College of \\ Pennsylvania, Department of Anatomy and Neurobiology, Philadelphia, Pennsylvania 19129, ${ }^{3}$ Thomas Jefferson University, \\ Philadelphia, Pennsylvania 19107, ${ }^{4}$ Gyeongsang National University, Chinju, Korea, and ${ }^{5}$ Department of Animal Biology, \\ University of Pennsylvania Veterinary School, Philadelphia, Pennsylvania 19104
}

\begin{abstract}
Pseudorabies virus (PRV) has been used extensively to map synaptic circuits in the CNS and PNS. A fundamental assumption of these studies is that the virus replicates within synaptically linked populations of neurons and does not spread through the extracellular space or by cell-to-cell fusion. In the present analysis we have used electron microscopy to characterize pathways of viral replication and egress that lead to transneuronal infection of neurons, and to document the non-neuronal response to neuronal infection. Three strains of PRV that differ in virulence were used to infect preganglionic motor neurons in the dorsal motor nucleus of the vagus (DMV). The data demonstrate that viral replication and transneuronal passage occur in a stepwise fashion that utilizes existing cellular processes, and that the non-neuronal response to infection serves to restrict nonspecific spread of virus by isolating severely infected neurons. Specifically, capsids containing viral DNA replicate in the cell nucleus, traverse the endoplasmic reticulum to gain access to the cytoplasm, and acquire a bilaminar membrane envelope from the trans cisternae of the Golgi. The outer leaf of this envelope fuses with the neuron membrane to release virus adjacent to axon terminals that synapse upon the infected cell. A second fusion event involving the viral envelope and the afferent terminal releases the naked capsid into the bouton. Systematic analysis of serial sections demonstrated that release of virus from infected neurons occurs preferentially at sites of afferent contact. Nonspecific diffusion of virus from even the most severely infected cells is restricted by astrocytes and other non-neuronal elements that are mobilized to the site of viral infectivity. The ability of glia and macrophages to restrict spread of virus from necrotic neurons is the product of (1) temporal differences in the mobilization of these cells to the site of infection, (2) differential susceptibility of these cells to PRV infection, and
\end{abstract}

\footnotetext{
Received Aug. 18, 1992; revised Dec. 3, 1992; accepted Dec. 17, 1992.

Work appearing in this article was supported by Du Pont Merck Pharmaceutical Company and NIH Grant GM27739 awarded to R.R.M. We gratefully acknowledge the insight provided by Dr. Pat Levitt. Mary Whealy, Henry Pautler, Claudia

Williams, and Janice Lancaster provided expert technical assistance.

Correspondence should be addressed to J. Patrick Card, Ph.D., Department of Behavioral Neuroscience, 446 Crawford Hall, University of Pittsburgh, Pittsburgh, PA 15260.

- Present address: Department of Behavioral Neuroscience, 446 Crawford Hall, University of Pittsburgh, Pittsburgh. PA 15260.

Copyright (C) 1993 Society for Neuroscience 0270-6474/93/132515-25\$05.00/0
}

(3) abortive viral replication in cells that are permissive for infection. The findings provide further insight into the intracellular routes of viral assembly and egress and support the contention that transneuronal spread of virus in the brain results from specific passage of virions through synaptically linked neurons rather than through cell fusion or release of virus into the extracellular space.

[Key words: pseudorabies virus, transneuronal transport, vagal motor neurons, glia, ultrastructure, immunocytochemistry]

Pseudorabies virus (PRV) is a swine $\alpha$-herpesvirus that has been used extensively to map neural circuits (Martin and Dolivo, 1983; Rouiller et al., 1986, 1989; Strack et al., 1989a,b; Card et al., 1990, 1991, 1992; Strack and Loewy, 1990; Jansen et al., 1992; Nadelhaft et al., 1992; Rotto-Percelay et al., 1992). Like other members of this family of viruses (i.e., herpes simplex virus), PRV exhibits a pronounced affinity for neurons that leads to uptake, replication, and transneuronal passage of virions. Productive infection of neurons produces cytopathic effects that could compromise the circuit related transport of virus. Consequently, knowledge of the intracellular pathways of viral assembly and egress, as well as the response of non-neuronal cells to neuronal infection are important considerations in evaluating the transport of virus through any neural circuit.

A substantial number of investigations have examined the morphological events of $\alpha$-herpesvirus assembly and egress in vitro (Morgan et al., 1959, 1968; Nii et al., 1968a,b; McCracken and Clarke, 1971; Miyamoto and Morgan, 1971; Fong et al., 1973; Smith and de Harvin, 1974; Johnson and Spear, 1982, 1983; Lycke et al., 1984, 1988; Marchand and Schwab, 1986; Lee et al., 1987; Jones and Grose, 1988; Pol et al., 1989, 1991 a,b; Whealy et al., 1991; Peeters et al., 1992). In addition, a limited number of studies have examined these processes in vivo (Field and Hill, 1974; Kristensson et al., 1974, 1978, 1982; Bak et al., 1977, 1978; Dolivo et al., 1978). Analysis of viral replication in immortalized pig kidney fibroblasts infected with PRV has demonstrated that acquisition of a bilaminar membrane from the trans cisternae of the Golgi complex may be a critical step in the replication of the virus (Whealy et al., 1991). Virions of similar morphology have becn identificd in cultured human sensory neurons infected with herpes simplex virus (HSV) (Lycke ct al., 1988). These studies suggest that release of infectious virus is dependent upon fusion of the outer membrane of the newly 
replicated virions with the plasma membrane of the infected cell. However, this hypothesis has not been established with certainty and the mode of intracellular transit and the precisc site of virion release in the CNS have not been examined in a systematic fashion.

Characterization of the route of viral passage through the nervous system is also dependent upon a thorough understanding of the cytopathic cvents associated with viral infection. Virulent and attenuated strains of HSV and PRV have been shown to induce neuropathological changes that ultimately lead to glial infection (Ugolini et al., 1987; Norgren and Lehman, 1989; Card et al., 1990, 1991, 1992; Strack and Loewy, 1990; Blessing ct al., 1991; Norgren et al., 1992; Rinaman et al., 1993), and it is becoming increasingly clcar that glia participate in the immune response to neurotropic viral infections (Massa et al., 1986, 1987a,b; Lieberman et al., 1989; Sarmiento and Klcincrman, 1990; Weinstein et al., 1990; Zuckermann et al., 1990). The extent to which these responses contribute to the isolation or spread of virus in the CNS has not been fully elucidated. Howcver, available evidence suggests that the non-neuronal response to infection serves to isolate afflicted neurons and thereby facilitates transsynaptic spread of virus (Ficld and Hill, 1974; Kristensson et al., 1974, 1978, 1982; Bak et al., 1977; Rinaman ct al., 1993). Nevertheless, ultrastructural analysis of the infected CNS is necessary to characterize fully the extent of virally induced pathology and elucidate further the roles that glia and macrophages play in determining the route of viral passage through the neuraxis.

In the present investigation we conducted a systematic ultrastructural analysis of the pathways of PRV replication, assembly and egress in the dorsal motor vagal (DMV) complex of the rat brainstem and characterized the non-neuronal response to viral infection. The DMV was chosen because we have fully characterized the temporal aspects of PRV transport in this circuit at the light microscopic level (Card et al., 1990; Miselis et al., 1991; Sternini et al., 1991; Rinaman ct al., 1993). In addition, the peripheral projections of DMV neurons and the ability to infect them by injecting virus into the wall of the stomach (Card et al., 1990) provide an ideal system for evaluating the CNS response to infection in the absence of the confounding physical insults that would occur if the virus were injected directly into the brain. The data provide new insights into $\alpha$-herpesvirus assembly, transport, and pathogenesis and are consistent with the conclusion that the non-neuronal response to infection isolates infected neurons and thereby supports specific transport of PRV through synaptically linked populations of neurons.

\section{Materials and Methods}

Animals. Adult male Sprague-Dawley rats $(200-300 \mathrm{gm}$ body weight at death) were used in this investigation. The animals were maintained in a standardized environment throughout the experiment (12 hr light; light on at 0600 ) with food and water freely available. Procedures for the maintenance and use of experimental animals conformed to the regulations detailed in the NIH Guide for the Care and Use of Laboratory Animals. Experimental protocols involving use of the virus were approved by our Animal Welfare Committee, which is subject to the rules and regulations of the American Association for Accreditation of Laboratory Animal Care and those stipulated in the Animal Welfare Act (Public Law 99-198). All surgeries were conducted on deeply anesthetized rats using aseptic procedures.

Safety procedures. Procedures for use of virus in these experimental paradigms have been published previously (Card et al., 1990, 1991). Nevertheless, it is important to reiterate that specialized facilitics and procedures are necessary for experiments employing herpesviruses. In the present studies, all work with PRV was confined to a Biosafety Level 2 (BSL-2) containment facility dedicated exclusively to this work. The conduct of experiments in this laboratory conformed to the BSL-2 regulations detailed in Health and Human Services Publication No. 888395 (Biosafety in Microbiological and Biomedical Laboratories). All animals were confined to the BSL-2 laboratory throughout the course of the analysis and infectious virus was inactivated in each animal at death by transcardiac infusion of buffered aldehyde solutions (see below).

Preparation of PRV. Three strains of pseudorabies virus (PRV-Becker, PRV-4, and PRV-Bartha) were used. The Becker strain of virus (PRV$\mathrm{Be}$; Becker, 1967) is a virulent field isolate that we have previously used to define a multisynaptic brainstem circuit involved in gastric function (Card et al., 1990). PRV-Bartha (PRV-Ba; Bartha, 1961) is an attenuated, vaccine strain that possesses two prominent alterations in the viral genome that contribute to a reduction in virulence and longer postinoculation survival intervals (Card et al., 1992). PRV-4 is a virulent strain derived from PRV-Be containing a mutation in the viral envelope glycoprotcin glll gene. Previous analysis has shown that PRV-4 is as virulent as PRV-Be when injected into the vitreous body of the eye (Card et al., 1992). All strains were grown in pig kidney fibroblasts to titers of $6 \times 10^{8} \mathrm{pfu} / \mathrm{ml}$ (PRV-Be). $5 \times 10^{8} \mathrm{pfu} / \mathrm{ml}(\mathrm{PRV}-\mathrm{Ba})$, and $7 \times$ $10^{\prime} \mathrm{pfu} / \mathrm{ml}$ (PRV-4).

Experimental paradigms. Rats were infected by injecting $1-6 \mu \mathrm{l}$ of virus into the ventral wall of the stomach as described previously (Card et al., 1990). The extent of transport of each strain of PRV was assessed by injecting animals with equal volumes of the same viral stocks and processing the brainstems for light microscopic immunohistochemistry or for electron microscopic analysis. Animals injected with PRV-Be werc killed $48 \mathrm{hr}$ following inoculation, while those inoculated with PRV-4 and PRV-Ba were killed at 53 and $65 \mathrm{hr}$, respectively.

Animals inoculated with PRV-4 were simultaneously injected with 7 $\mu \mathrm{l}$ of $0.25 \%$ cholera toxin conjugated to horseradish peroxidase (CTHRP). CT-HRP is transported through both the motor and sensory components of the vagus nerve and enzymatic reaction of tissuc with diaminobenzidine produces an electron-dense reaction product that identifies labeled perikarya and processes at the ultrastructural level (Rinaman et al., 1989). We used the CT-HRP reaction product to identify DMV motor neuron perikarya and processes to determine the extent of intracellular transport of newly replicated virus in infected neurons.

Immunoperoxidase localizations. A rabbit polyclonal antiserum raised against PRV and the avidin-biotin modification (Hsu et al., 1981) of Sternberger's (1979) immunoperoxidase method were used to localize viral epitopes. Specific details of antibody specificity and application of this method for light microscopic immunohistochemical localization of PRV in the DMV have been published (Card et al., 1990).

Ulirastructural preparation. Animals were anesthetized and perfused transcardially with buffered aldehyde solutions as previously described (Card et al., 1986). Thercafter, each brain was removed from the cranium and postfixed in the primary fixative overnight at $4^{\circ} \mathrm{C}$, and the caudal brainstem was sectioned serially in the coronal plane with a vibratome ( $100 \mu \mathrm{m}$ per section). Tissuc sections were washed in buffer, postfixed in a $1 \%$ osmium tetroxide solution containing $1.5 \%$ potassium ferricyanide (Langford and Coggeshall, 1980), dehydrated, infiltrated, and flat-embedded in Epon-Araldite plastic resin. Sections at the level of the area postrema were trimmed to a trapezoid including the DMV and nucleus of the solitary tract (NST) and sectioned with a Reichert Jung ultramicrotome using a diamond knife. Thick sections $(0.5 \mu \mathrm{m})$ were cut, mounted on slides, stained with toluidine blue, and photographed with a Reichert Jung Polyvar photomicroscope. Ultrathin sections of areas immediately adjacent to the thick sections were picked up on Formvar-coated slot grids, stained with lead citrate and uranyl acetate, and analyzed and photographed with a JEOL 1200EX transmission electron microscope

A serial series of 1535 consecutive ultrathin sections was collected from the animal infected with PRV-Bartha. This series was used to examine the same profiles in adjacent sections in order to gain a thorough understanding of virion assembly, intracellular transport, and release.

$C T-H R P / P R V$ injections. The two animals injected with a cocktail of PRV-4 and CT-HRP were anesthetized and killed by transcardiac perfusion fixation $53 \mathrm{hr}$ after inoculation. One animal was perfused with sequential transcardiac infusions of dilute $(0.1 \%$ paraformaldehyde, $0.5 \%$ glutaraldehyde in $0.1 \mathrm{M}$ sodium phosphate buffer) and concentrated ( $5 \times$ the concentration of the dilute) fixative. The brain was then removed, postfixed for $\mathrm{I} \mathrm{hr}$, washed in phosphate buffer overnight, and sectioned in the coronal plane with a vibratome $(50 \mu \mathrm{m} /$ section). The tetramethyl- 
benzidine method of Mesulam (1982) was used to localize HRP in cvery third section through the DMV/NST. These sections were mounted on gelatin-coated slides, air dried, and coverslipped for light microscopic analysis. The remaining sections were reacted with diaminobenzidine and $\mathrm{H}_{2} \mathrm{O}_{2}$ to visualize the HRP and processed for electron microscopy (Rinaman et al., 1989). The other animal was perfused with $4 \%$ paraformaldehyde and $0.2 \%$ picric acid in $0.1 \mathrm{~m}$ sodium phosphate buffer and processed for light microscopic immunohistochemical localization of virus and CT-HRP conjugate. Virus was localized with the rabbit polyclonal anti-PRV antiserum, and a goat antiserum raised against cholera toxin (Calbiochem) was used to localize the CT-HRP conjugate. The virus antiserum was diluted to $1: 1000$ with phosphate buffer containing 1\% normal goat serum and $0.3 \%$ Triton X-100; the CT antiserum was diluted to 1:5000 with $1 \%$ normal rabbit serum and $0.3 \%$ Triton $\mathrm{X}-100$ using the same buffer. Both antigens were visualized with fluorescence histochemistry using either rhodamine- or FITC-conjugated secondary antisera.

Ultrastructural analysis. Each ultrathin section was subjected to a systematic method of analysis designed to characterize fully the extent of viral infection in the DMV/NST complex. This method was previously used to characterize the synaptic organization of vagal gastric motor and sensory afferents in this region of brainstem (Rinaman et al., 1989). Specific details regarding sampling are available in that publication, but it is worthwhile to reitcrate the most important aspects of the method and to detail those unique to the present study. A critical feature of the analysis involved correlating light and electron microscopic data. Thick sections $(0.5 \mu \mathrm{m})$ from arcas immcdiatcly adjacent to the ultrathin sections were photographed and used to direct the ultrastructural analysis. Landmarks evident in those photomicrographs (i.e., blood vessels, myelinated fiber tracts, motor neurons) were used to identify precisely the region examined at the ultrastructural level. The DMV was initially examined at $5000 \times$ in sequential passes through the nucleus to identify infected neurons and basic features of virally induced neuropathogenesis. The analysis was then repeated at $20,000 \times$ to characterize the synaptic organization of the DMV and the morphology of infected profiles. The same method of analysis was applied to the NST, the tractus solitarius, and the ventrolateral region adjacent to the DMV that contains efferent axons of vagal motor neurons.

\section{Results}

Examination of viral transport with light microscopic immunohistochemistry demonstrated that the extent of viral transport in the dorsal motor vagal complex was equivalent for each of the three strains of PRV, even though the postinoculation interval was longer in the animal infected with the attenuated strain. This finding confirms our previous demonstrations that the temporal course of infection produced by attenuated virus lags behind that produced by virulent strains (Card et al., 1992; Rinaman et al., 1993). Following injection of the ventral stomach wall, all three strains of PRV infected substantial numbers of motor neurons in the left DMV and scattered motor neurons in the right DMV. Neurons in the medial subfield of the NST were also infected, but there were no infected cells in other regions of the neuraxis at these early survival times. This pattern of infection was also observed in the animals injected with both PRV-4 and CT-HRP, but the CT-HRP reaction product was confined to motor neurons and primary sensory afferents.

\section{Pathological hallmarks of viral infection}

Light and electron microscopic examination of the DMV revealed a number of prominent signs of viral infection. These included pathological inclusions in the nuclei of infected neurons, ruffling and invaginations of the nuclear membrane, enlargement of the perivascular space, and the presence of small intensely staining cells adjacent to the vascular endothelium and in the neuropil (Fig. $1 B-D$ ). Virally induced changes in neuronal morphology were confined to the DMV and NST, while morphological alterations in the vasculature and the small densely staining cells also were apparent in regions bordering upon the
DMV and NST. These pathological changes were present in the DMV of all infected animals, but they were more prevalent in animals infected with the virulent strains of PRV. Dense degeneration of chronically infected DMV neurons was only observed in the animals infected with the virulent strains of virus.

\section{Virus replication, assembly, and egress in neurons}

Capsid formation. The appearance of viral capsids in cell nuclei was among the first morphological changes in infected ncurons (Fig. 2). Chromatin became clumped and marginated, the nucleolus dispersed, the nuclear envelope proliferated and developed increasingly complex invaginations, and the progressive increase in capsids produced pathological inclusions in the cell nuclei. Individual nucleocapsids consisted of electron-dense cores of viral DNA within structural protein cages (Fig. $3 A$ ). The structural protein cage was approximately $8 \mathrm{~nm}$ thick and the entire cross-sectional diameter of mature capsids was $100 \mathrm{~nm}$. Capsids occurred individually, in large aggregations, and in paracrystalline arrays adjacent to the nuclear membrane. In the larger aggregations, they were often enmeshed in a granular matrix that varied from a light homogeneous meshwork to dense concentrations of $20 \mathrm{~nm}$ granules (Fig. 3A).

Analysis of neurons in serial thin sections demonstrated that the nucleus of every infected cell contained distinct sites of capsid assembly. Complex interwoven masses of tubules were the principal constituent of these areas (Fig. 3B,C). Cross-sectional profiles of individual tubules presented a spherical to slightly oblong conformation with a widest diameter of 10-15 $\mathrm{nm}$, and the entire tubule mass was a few micrometers in size. Within each of these areas, multiple tubules formed concentric rings around regions of coalescing viral DNA (solid arrows in Fig. $3 B, C$ ). Fully assembled capsids were present at the periphery of the tubule mass, sometimes with individual tubules associated with the superficial aspect of the structural protein cage (open arrow, Fig. 3C).

Capsid transport to the cytoplasm. Our data support the conclusion that nucleocapsids gain access to the cytoplasmic compartment of the cell by budding through the inner membrane of the nuclear envelope, traversing the endoplasmic reticulum (ER), and deenveloping to exit the ER in the vicinity of the Golgi complex. As noted above, large numbers of capsids were observed adjacent to the inner nuclear membrane, often in paracrystalline arrays that filled a lobule of the nucleus created by pathological invagination of the nuclear envelope. In addition, we observed individual capsids budding through the inner leaf of the nuclear envelope to acquire a spherical membrane envelope (Fig. 3D). These enveloped virions were $120-160 \mathrm{~nm}$ in widest diameter and were routinely observed between the two leaves of the nuclear envelope, either individually or in groups.

Cells advanced in the course of viral infection exhibited vast arrays of ER that extended throughout the cytoplasm. Only small Nissl bodies were present in uninfected DMV neurons from control material and were rare in neurons infected with PRV. Thus, it is unclear whether the extensive ER networks in infected neurons werc the product of membrane proliferation or simply represented disassembly of Nissl bodies. In any event, infected cells displayed highly interconnected trabeculae of ER that were continuous with the nuclear membrane at multiple sites. In many instances, enveloped capsids between the leaves of the nuclear envelope passed into the ER (Fig. $3 E$ ), and linear stretches of ER in the cytoplasm contained membrane-limited capsids that were similar in size and morphology. Portions of 


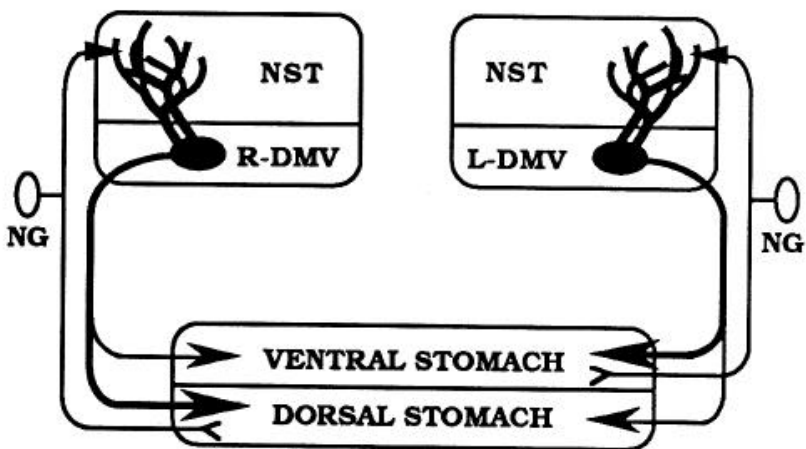

$\mathbf{A}$

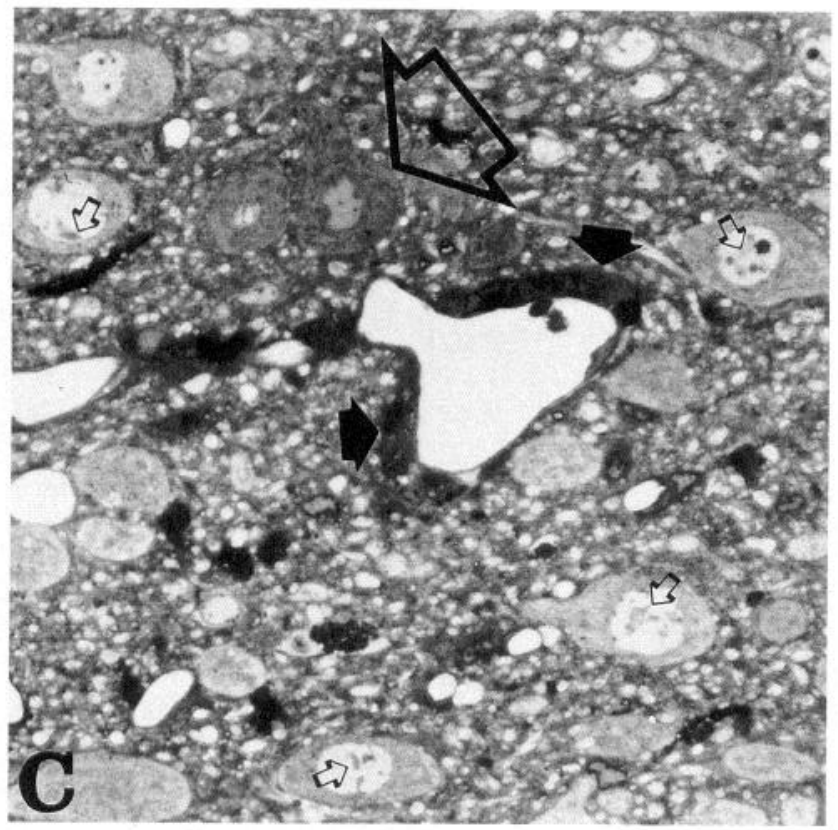

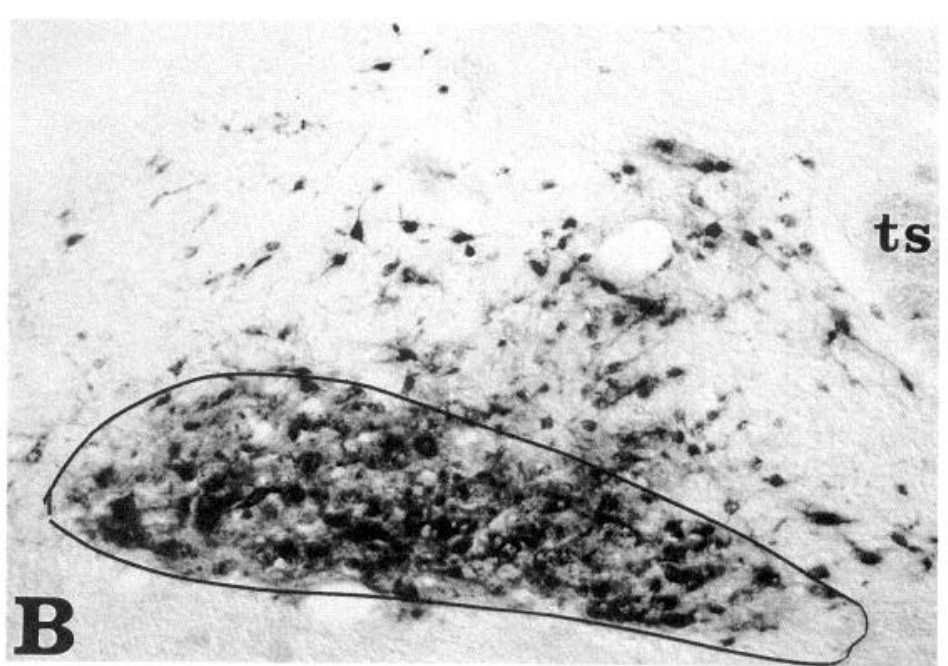

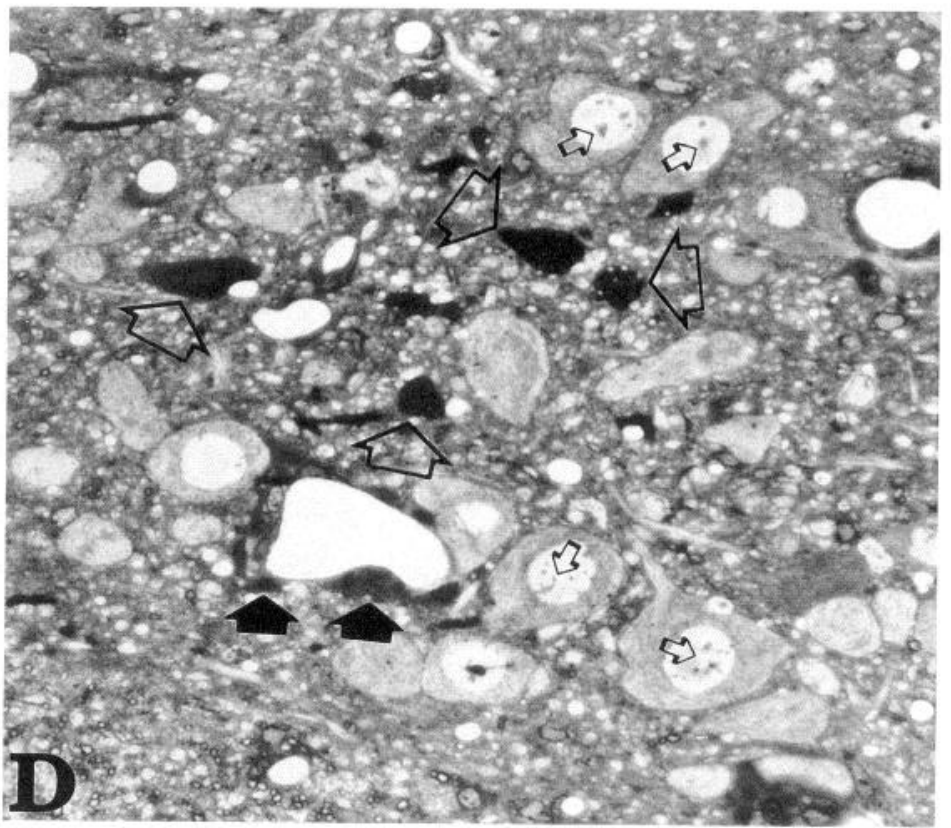

Figure 1. A illustrates the organization of vagal circuitry that innervates the stomach. The dorsal wall of the stomach is innervated predominantly by motor neurons in the right DMV; the left DMV provides the primary innervation for the ventral wall. Sensory afferents in the stomach arise from neurons in the nodose ganglion $(N G)$, and these cells also give rise to a process that passes through the tractus solitarius $(t s)$ to synapse on DMV dendrites and neurons in the NST. $B$ is a light microscopic immunohistochemical localization of PRV-Ba in the left DMV/NST 65 hr following injection of the virus into the ventral stomach musculature. The solid line defines the boundaries of the DMV. Substantial numbers of DMV neurons exhibit PRV immunoreactivity, and the virus has also passed transneuronally to infect presynaptic neurons in the overlying NST. $C$ and $D$ are photomicrographs of $0.5 \mu \mathrm{m}$ sections from the DMV of an animal infected with PRV-4 $53 \mathrm{hr}$ prior to death. Infected motor neurons characteristically exhibit pathological inclusions in the cell nuclei (small open arrows). Increased cytoplasmic density (large open arrow in C) or shrunken electron-dense profiles (large open arrows in $D$ ) reflect more advanced pathology. The other hallmark of infection by virulent strains of virus includes increases in the density and thickness of the vascular wall (solid arrows in $C$ and $D$ ) and the presence of small osmophilic cells in the neuropil.

ER continuous with the nuclear envelope were studded with ribosomes, but gave way to complex trabecular networks of smooth ER further into the cytoplasm. Virions were present throughout the full extent of these trabeculae.

The passage of enveloped virions into the ER was followed by fusion events that released naked nucleocapsids into the cytoplasm near the trans cisternae of Golgi complexes (Fig. 4A). Profiles of smooth ER containing single enveloped virions were prevalent in the vicinity of the Golgi, and release of capsids from the ER by fusion of the virion membrane with the ER was a common observation. Additionally, the Golgi complex was the most frequent site of capsid accumulation in the cytoplasm.

Envelopment of capsids. The final envelopment of capsids occurred at the Golgi complex. This process endowed capsids with a bilaminar membrane envelope that permitted them to leave the parent cell and gain access to other cells in the CNS. Application of this envelope occurred by wrapping of Golgiderived membrane around individual capsids. Following fusion-induced release of capsids from the ER (Fig. 4A), naked capsids accumulated adjacent to the polar aspects of the Golgi 


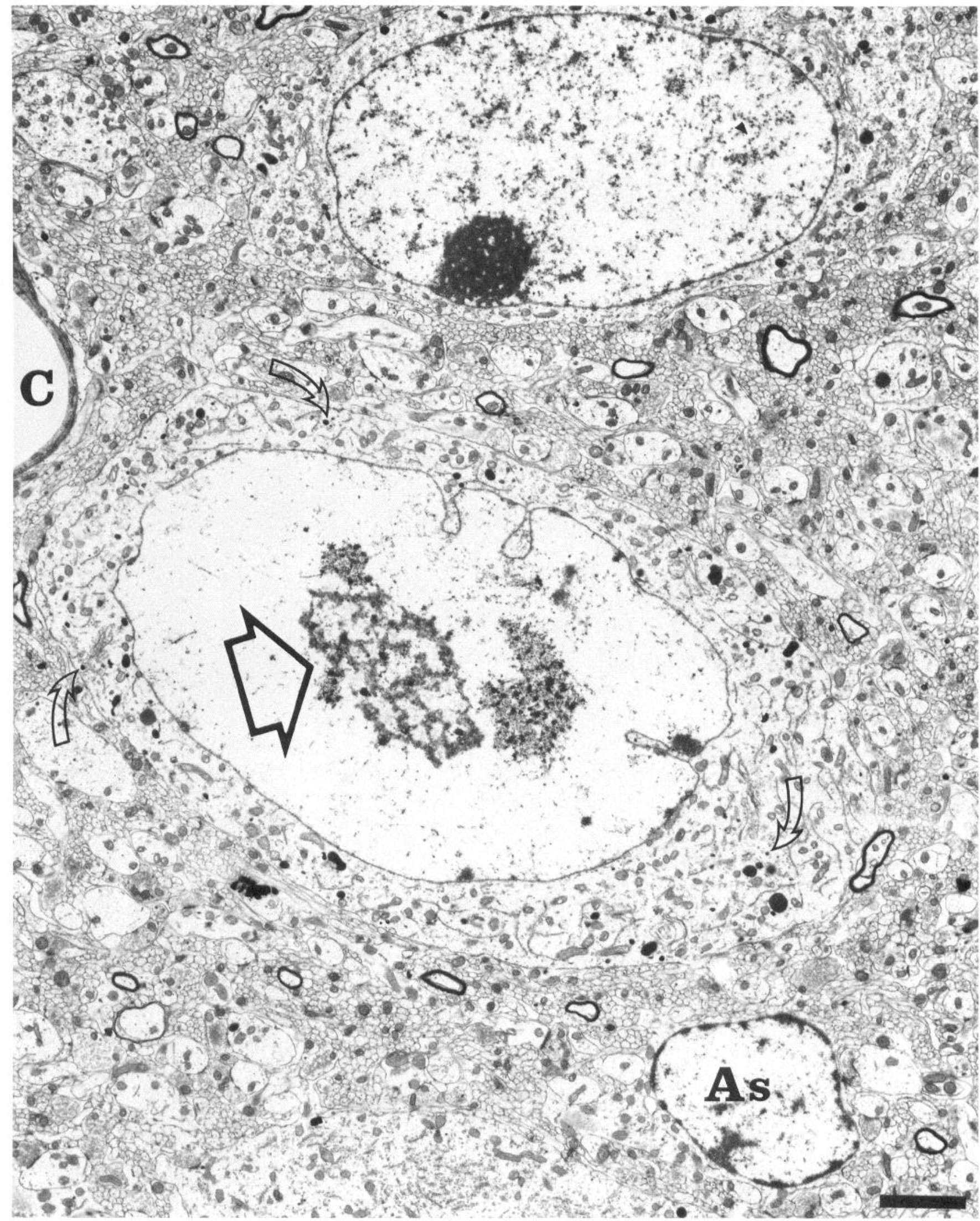

Figure 2. Forty-eight hours following injection of $1 \mu \mathrm{l}$ of PRV-Be into the ventral wall of the stomach, a parasympathetic neuron in the DMV illustrates morphological characteristics typical of virus-infected neurons. Mature virions in the cytoplasm are difficult to resolve at this low magnification. However, pathological invaginations of the normally smooth nuclear envelope and dense intranuclear inclusions (arrow) resulting from virus infection are clearly apparent. The neuron in the upper portion of the field shows no overt morphological signs of infection, and the organization of the neuropil appears relatively normal in spite of the virulence of the virus and the $48 \mathrm{hr}$ postinjection survival interval. $A s$, astrocyte; $C$, capillary. Scale bar, $2 \mu \mathrm{m}$. 

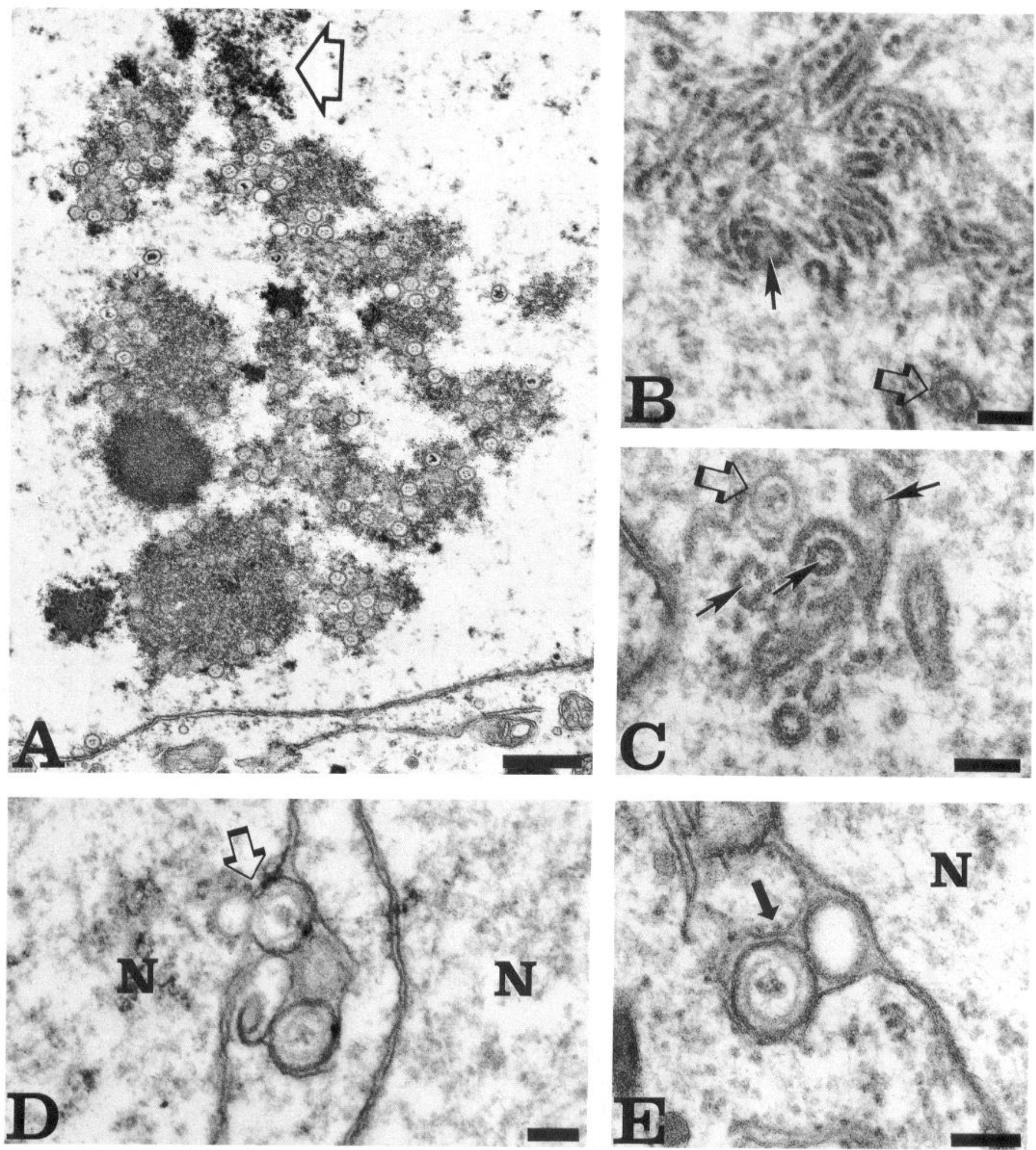

Figure 3. Viral replication and egress from the nucleus of an infected DMV neuron are illustrated. $A$ demonstrates that the large inclusions in the nuclei of infected cells (see Fig. 1) are composed of viral capsids. These nucleocapsids consist of electron-dense cores of viral DNA surrounded by virally encoded structural protein capsules. Aggregations of capsids are often enmeshed within a dense homogeneous matrix (arrow). $B$ and $C$, Intranuclear tubule masses provide focal sites for capsid assembly. Individual tubules exhibit an average cross-sectional diameter of $10-15 \mathrm{~nm}$ and surround sites at which viral DNA coalesces (solid arrows). The open arrows show mature virions at the periphery of tubule masses. $D$ and $E$, Capsids' egress from the cell nucleus is accomplished by budding through the inner leaf of the nuclear envelope (arrow in $D$ ) to acquire a single membrane envelope and pass into the rough ER (arrow in $E$ ). $N$, nucleus. Scale bars: $A, 400 \mathrm{~nm} ; B-E, 100 \mathrm{~nm}$. 
and became intimately associated with individual cisternae at the trans face of this organelle (Fig. $4 B-D$ ). Most commonly, distinctive $C$-shaped segments at the peripheral aspect of a Golgi cistern surrounded individual capsids and ultimately fused to produce a bilaminar envelope (Fig. $4 C$ ). A particularly interesting aspect of this process was the distinct morphology exhibited by the portion of the Golgi membrane involved in envelopment. In most cases, the segment of trans cistern destined to wrap a capsid exhibited prominent membrane decorations (Fig. $4 B-D$ ). This coat was approximately $15 \mathrm{~nm}$ thick, and the dense granular components of the coat exhibited a regular periodicity at about $10 \mathrm{~nm}$ intervals.

Wrappings of the capsids with trans Golgi cisterns produced virions with an average cross-sectional diameter of $200 \mathrm{~nm}$. Both membranes of this envelope were easily resolved in newly wrapped virions, and the average distance between the inner and outer membrane was $20-25 \mathrm{~nm}$. The outer membrane characteristically exhibited the membrane decorations found on the Golgi cistern that had wrapped it, a feature that provided a reliable means of distinguishing these profiles from the membrane enclosed virions traversing the ER. However, it should be emphasized that there were instances in which the membrane decorations were absent from trans Golgi membrane involved in capsid envelopment.

Lysosomal targeting of virions. All infected neurons exhibited complex lysosomal inclusions that were filled with enveloped virions in various states of degradation (Fig. 5). These inclusion bodies were concentrated in the peripheral aspects of the cell soma and generally consisted of multiple interconnected electron-dense lobules. Bilaminar enveloped virions fused with these larger lysosomal inclusions and released capsids surrounded by a single membrane envelope into the electron-dense core of the inclusion. These inclusions were evident in neurons at all stages of infection and were one of the early morphological indicators of viral infection. However, in spite of the prevalence of these inclusions, and the large number of virions that they contained, we never observed them fusing with the external limiting membrane of a neuron to release their contents into the extracellular space. Furthermore, the necrotic statc of virions within each inclusion suggested that they represented a degenerative endpoint rather than a vehicle for bulk delivery of virions to the plasma membrane.

Intracellular transport of mature virions. Mature virions were observed throughout the perikarya of infected neurons and in the primary dendrites extending from those cells (Fig. 5). However, the morphology of virions changed substantially as they moved away from the Golgi complex and entered other portions of the cell soma and dendritic tree. In particular, the Golgiderived external coat was not apparent on the outer membrane of the envelope, the space between the inner and outer mem- branes was reduced in size and increased in density, and the entire virion was more spherical in conformation. This maturation process produced a particle of smaller cross-sectional diameter (approximately $180 \mathrm{~nm}$ ) in which it was sometimes difficult to resolve the two membranes composing the envelope (Figs. 5, 6A-E).

Characterization of the full extent of transport of enveloped virions through the dendritic tree of infected DMV neurons was determined by ultrastructural analysis of tissuc from the animal that received dual injection of PRV-4 and CT-HRP. The electron-dense chromagen resulting from histochemical localization of CT-HRP was used to identify dendrites of gastric motor neurons in the DMV and overlying NST. Systematic examination of these areas at $20,000 \times$ revealed numerous labeled primary, intermediate, and distal dendrites that also contained enveloped virions (Fig. 6A-C). All of these virions were approximately $180 \mathrm{~nm}$ in widest diameter, and careful examination demonstrated that their dense envelope was composed of two membranes separated by a small electron-dense space. Thus, it is apparent that newly replicated virions are transported through the full extent of the dendritic tree. Whether this transport is active or occurs by passive diffusion cannot be determined from the present data.

Material from the CT-HRP/PRV-4 experiment was also analyzed to determine the morphology of virions in axons of motor neurons and in sensory axons of the tractus solitarius. The axons of motor neurons at the ventrolateral extent of the DMV only contained naked capsids (Fig. $6 E$ ), indicating that capsids gained access to motor axon terminals in the stomach wall by fusion of the virion envelope with the axonal membrane, and that capsids were not incorporated in a vesicle for retrograde transport to the neuronal cell body. The absence of enveloped virions in motor axons further suggested that newly replicated virions were differentially sorted to the dendrites of infected cells and were not transported into the axon within this survival interval. In contrast, the few sensory axons in the tractus solitarius that contained virions at this early survival time had a bilaminar envelope (Fig. 6D). This observation suggests that, following retrograde transport of capsids from the stomach to sensory neurons in the nodose ganglia, virus replicated in these peripheral neurons and virions acquired a Golgi-derived envelope before being transported anterogradely to the NST.

Transneuronal passage of virus. Virions with bilaminar membrane envelopes were observed throughout the perikarya and dendritic arbors of infected DMV neurons. These profiles and the surrounding neuropil were examined (often in serial series of electron micrographs) to elucidate the site of virion release and to determine if virions were free within the extracellular space. This analysis demonstrated that virions were frequently released at sites of afferent synaptic contact, but did not gain

Figure 4. The process by which virions are released into the cytoplasm and enveloped at the Golgi complex is shown in the schematic diagram, and selective aspects of the process are shown in the accompanying electron micrographs. $A$ illustrates a virion in a cistern of smooth ER (solid arrows). Naked capsids released into the cytoplasm by fusion of the virion envelope with a segment of smooth ER are shown at the open arrows. $B-D$ illustrate the application of bilaminar envelopes to capsids ( $B$ and $C$ are cross sections through Golgi profiles; $D$ is a horizontal section through the trans portion of the Golgi). Trans cisterns of the Golgi wrap naked capsids (open arrows). These membranes are continuous with trans cisternae (open arrow in $C$ and solid arrow in $D$ ). Note also that membranes wrapping the capsids are decorated with a spiked coat that is limited to that portion of the trans cistern surrounding the capsid (best illustrated in $C$ and $D$ ). Scale bars: $A$ and $C, 100 \mathrm{~nm} ; B$ and $D .200 \mathrm{~nm}$.

Figure 5. Two infected DMV motor neurons are illustrated. A large primary dendrite emanates from one of the neurons in the center of the field. The boxed area is shown at higher magnification in the lower inset and illustrates the large number of mature virions that are present in this segment of the dendrite (see Results for detailed description of morphology). Virions in various stages of degeneration are also present in interconnected Iysosomal inclusions (upper inset) and multilaminar glial sheaths surround the cell soma (arrows). Scale bar, $1 \mu \mathrm{m} ;$ lower inset scale bar, $500 \mathrm{~nm}$; upper inset scale bar, $200 \mathrm{~nm}$. 


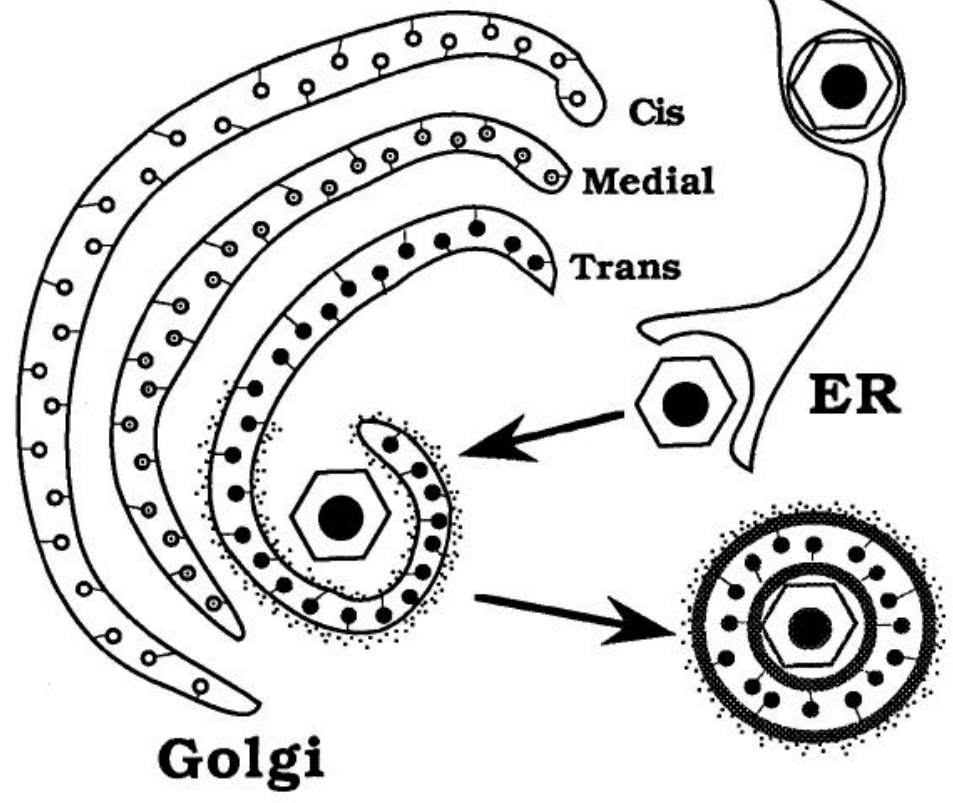

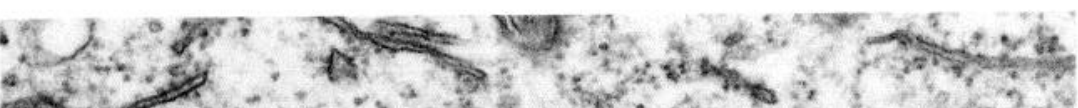

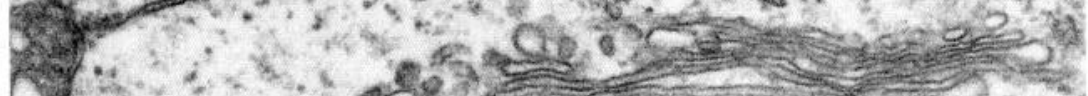

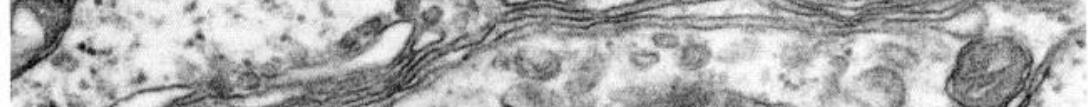

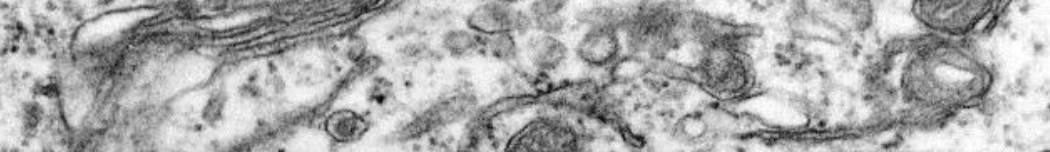

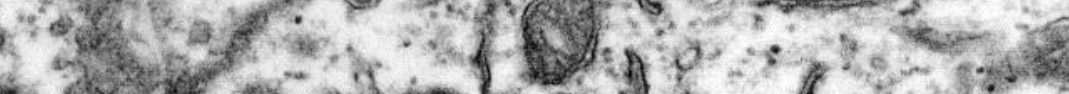

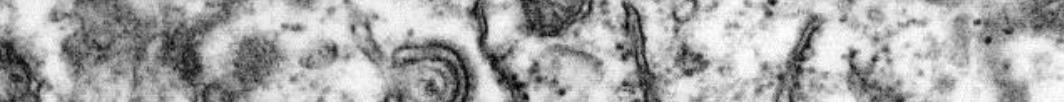

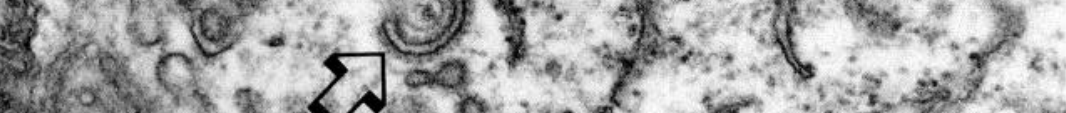

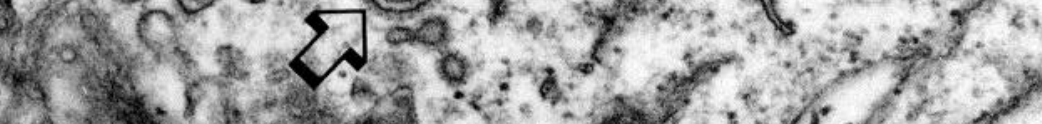

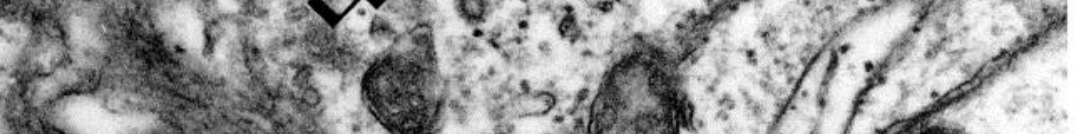

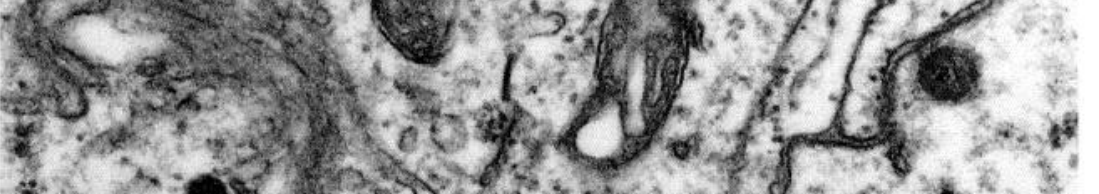

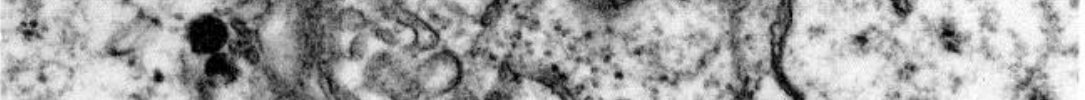

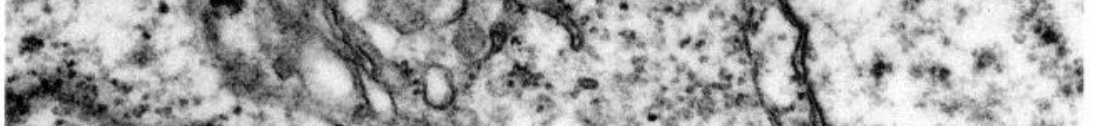

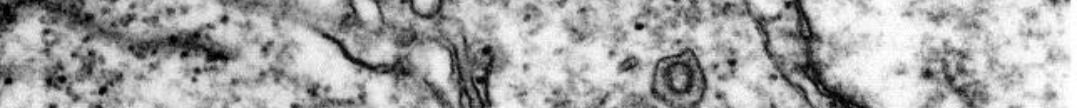

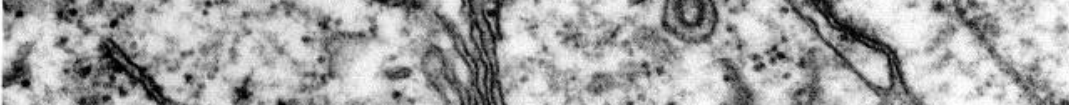

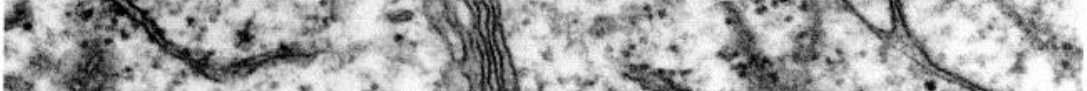

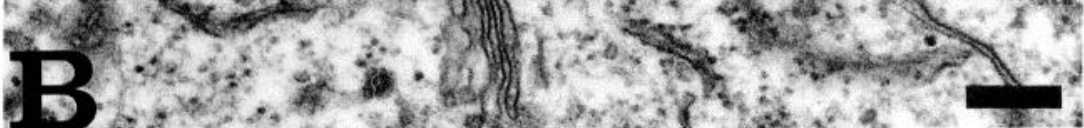
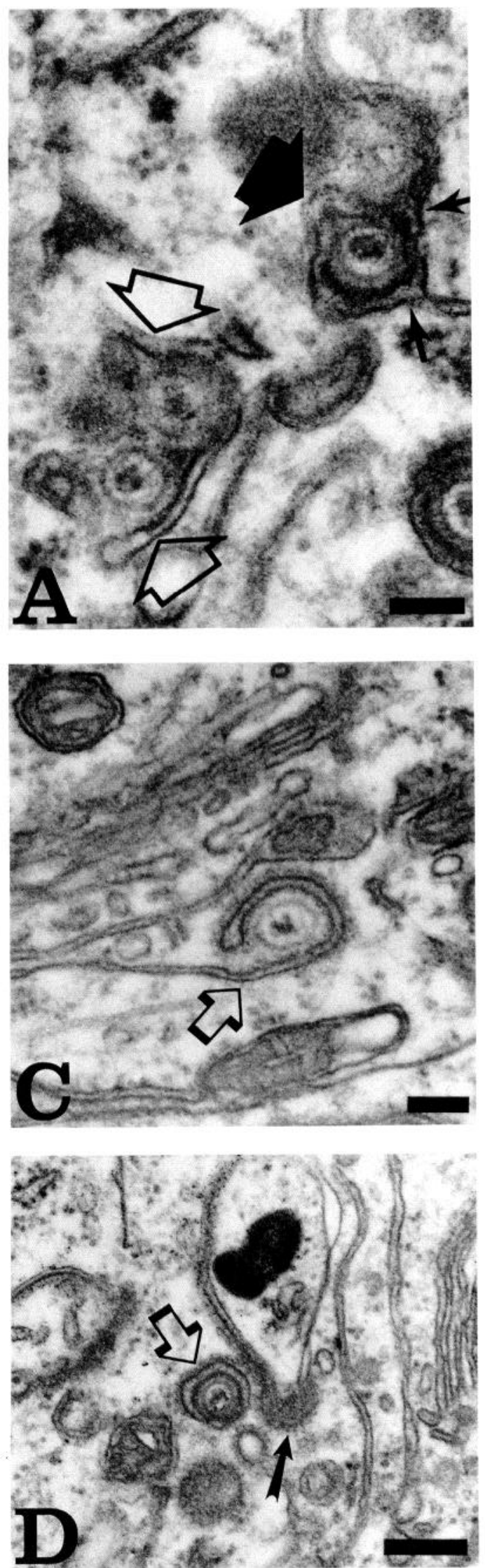


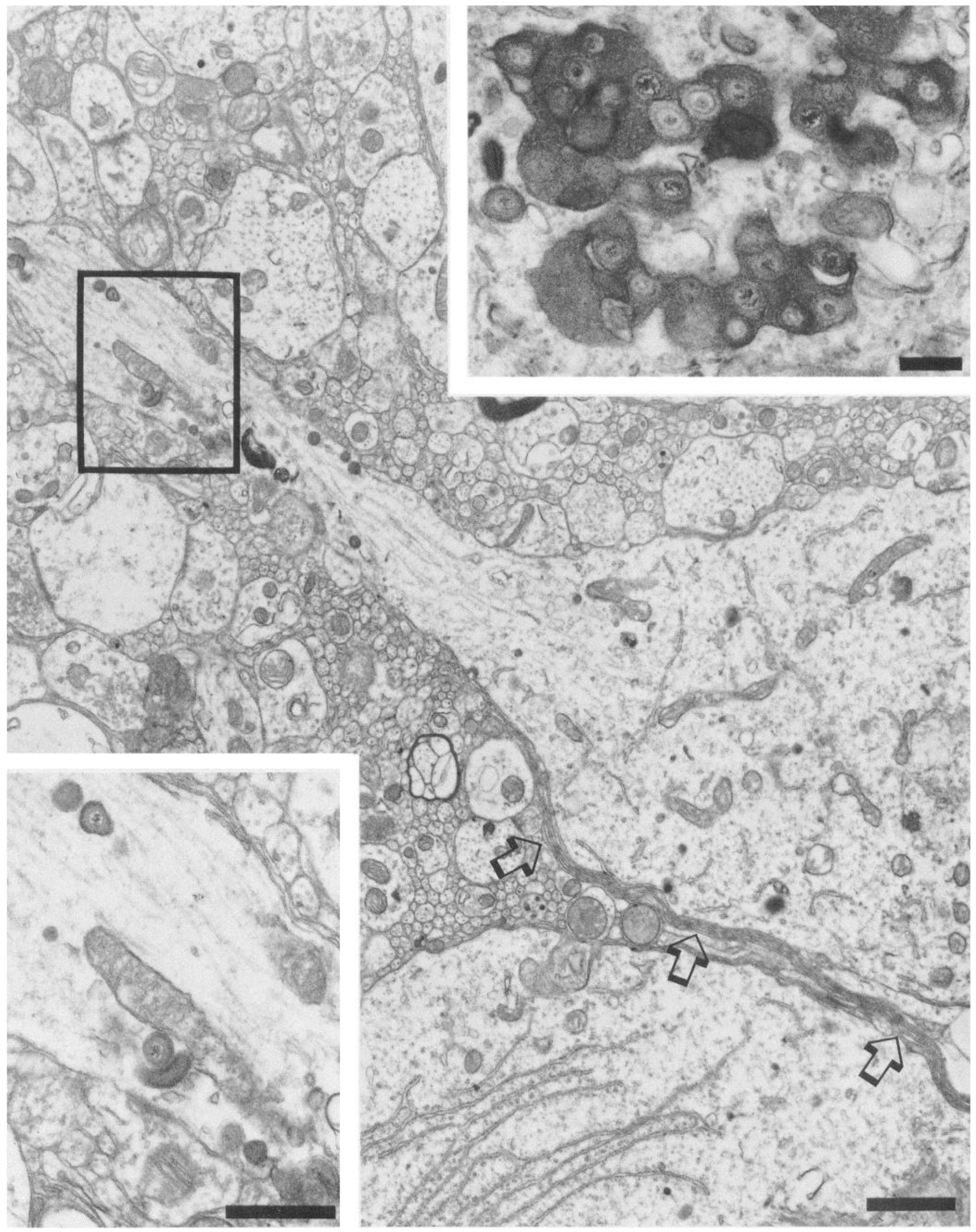


access to the extracellular space. This was true of all infected neurons, even those exhibiting advanced pathology. Furthermore, the data demonstrated that virions did not discriminate among the morphologically distinct classes of axon terminals that synapsed upon the soma and dendrites of infected neurons. Viral egress was observed in relation to all classes of terminals throughout the full extent of the dendritic arbor.

Our observations indicate that the bilaminar nature of the Golgi-derived envelope is essential for release of virions from the infected neurons as well as for the subsequent invasion of afferent terminals. This process involves two fusion events in which (1) the outer membrane of the virion fuses with the membrane of the infected cell to release infectious virus adjacent to the afferent terminal, and (2) the remaining membrane of the viral envelope fuses with the afferent to deposit the capsid into the terminal (see schematic inset of Fig. 7). All the elements of this process are shown in Figures 7 and 8 . The bilaminar enveloped virion initially comes in close proximity to the site of afferent contact (Fig. $7 A$ ), the outer membrane of the virion fuses with the plasma membrane to relcase the virion adjacent to the terminal (Figs. $7 B-D, 8 C$ ), and the remaining membrane of the envelope fuses with the terminal to release the capsid into the afferent (Figs. $7 E, 8 C$ ). Our data also indicate that more than one virion may cross into a single afferent (Fig. $8 \mathrm{~A}-\mathrm{C}$ ) and that passage of multiple virions through a single site leads to pronounced buildup of membrane that marks the site of transneuronal passage (Fig. $7 F$ ). These areas of membrane accumulation were present throughout the DMV/NST neuropil.

\section{Neuropathogenesis and the non-neuronal response to neuronal infectivity}

Astrocytes, microglia, and macrophages exhibited a prominent response to viral infection of DMV neurons. Systematic examination of the neuropil revealed that all three of these cell types were prevalent in the DMV of animals infected with virulent strains of PRV. In contrast, although reactive astrocytes and microglia were routinely observed in the DMV of the animal infected with attenuated virus, macrophages were rare at this carly survival interval. This finding is consistent with our recent light microscopic characterization of the temporal response of these cells to infection of DMV neurons with attenuated and virulent strains of PRV (Rinaman et al., 1993).
Astrocytic response. Astrocytes exhibited a profound response to viral infection of DMV neurons, and this response appeared to play a prominent role in restricting spread of virus from the chronically infected neurons. Reactive astrocytes were found in every field of viral infection and were particularly prevalent in relation to neurons suffering the pathological consequences of infection with virulent strains of virus (see Fig. 13). They exhibited the classical reactive morphology that has been previously characterized in response to neuronal injury (del RioHortega and Penfield, 1927; Duffy, 1983). This included an increase in cell size and claboration of largc, filament-laden processes that permeated throughout the neuropil. In many instances, the perikarya of these cells were directly apposed to the neurons exhibiting virally induced neuropathology (Fig. 10A).

At advanced stages of infection, the intimate relationships that astrocytes established with infected neurons eventually led to infection of the astrocytes themselves. Infected astrocytes exhibited all of the hallmarks of infection displayed by neurons with the important exception that enveloped virions were never observed in the cytoplasm of the astrocytc soma or its processes. Aggregations of nucleocapsids were prevalent in the cell nuclei (Fig. 10A), and these capsids used the nuclear membrane and ER in the same manner as neurons to gain access to the cytoplasm. However, in contrast to neurons, the ER of infected astrocytes became extremely distended (Fig. 10A-C). These edematous ER profiles contained capsids surrounded by a single membrane (Fig. $10 B$ ), and this membrane fused with the ER to release naked capsids into the astrocyte cytoplasm (Fig. 10C). In many instances, the external membrane surrounding the virion in the ER was covered by a spiked coat. This coat remained on the inner surface of the ER following membrane fusion and release of the capsid into the cytoplasm, thereby marking the site of release (Fig. $10 \mathrm{C}$ ). Large numbers of naked capsids were observed in the astrocyte cytoplasm (Fig. 10D) and individual capsids were present in the filament-laden processes of these cells. Nevertheless, well-structured Golgi cisternae were difficult to find in these cells, and there was never any evidence of capsid envelopment. In some instances, PRV infection of astrocytes induced dense degenerative pathology.

Microglia. Reactive, ramified microglia were also prevalent in the DMV of infected animals. Like astrocytes, these cells were found in all infected animals, but were more numerous in

\footnotetext{
Figure 6. This series of micrographs illustrates the morphology of virions in central motor and sensory vagal processes. The experimental paradigm and the circuitry are shown in the schematic diagram. A cocktail of virus (PRV-4) and CT-HRP conjugate was injected into the ventral wall of the stomach, and the animal was killed $53 \mathrm{hr}$ postinoculation. The electron-dense CT-HRP reaction product (solid arrows in $A-C$ ) permitted unambiguous identification of components of the vagal circuitry. The thick section to the right of the schematic is from the region immediately adjacent to the ultrathin sections analyzed with the electron microscope, and labeled arrows designate the region from which the corresponding electron micrographs were taken. Distal $(A)$, intermediate $(B)$, and proximal $(C)$ DMV dendrites all contain double-membraned virions (open arrows). Double-membraned virions are also present in a pathologically swollen sensory afferent $(D)$. The arrow in $D$ designates the virion that is shown at higher magnification in the inset. In contrast, myelinated efferent axons of DMV motor neurons $(E)$ only contain naked capsids. The solid arrow in $E$ designates a capsid that is shown at higher magnification in the inset, and the open arrow highlights another capsid that is pathologically swollen. $A P$, area postrema; $D M V$, dorsal motor vagal nucleus; $N S T$, nucleus of solitary tract; $t s$, tractus solitarius; $X I I$, hypoglossal nucleus. Scale bars: $A, B$, and $E, 200 \mathrm{~nm} ; C$ and $D, 500 \mathrm{~nm} ;$ insets, $100 \mathrm{~nm}$.

Figure 7. Several examples of transneuronal passage of virions are illustrated. The entire process is summarized in the schematic diagram. $A$ illustrates a newly wrapped virion in close proximity to an axosomatic afferent contact (arrow). Note the clear bilaminar nature of the viral envelope. $B-D$ illustrate virions that have been released from DMV motor neurons adjacent to sites of afferent contact (arrows). $E$ illustrates an unenveloped capsid (arrow) within an afferent synapsing upon an infected neuron, and $F$ illustrates the pronounced accumulation of membrane in regions where multiple virions pass transneuronally at the same site. The arrow in $F$ points to a virion. Scale bars: $D, 100 \mathrm{~nm}$; all other bars, $200 \mathrm{~nm}$.

Figure 8. $A-C$ are from a serial series through the same site of axodendritic contact. The animal was killed 65 hr postinoculation with PRV-Ba. An axodendritic contact in the boxed area of $A$ is shown at higher magnification in $B$ and in another plane of section in $C$. Three areas (arrowheads in $B$ ) of transneuronal passage of virions are shown in glazing sections through the virions. A free virion is also apparent in the dendrite (arrow). In $C$, a capsid enclosed by a single membrane is interposed between the infected dendrite and the same axon terminal (open arrow and shown at higher magnification in the inset) and a free capsid is present in the afferent (solid arrow). Scale bars: $A, 500 \mathrm{~nm} ; B, 200 \mathrm{~nm} ; C, 100 \mathrm{~nm}$.
} 

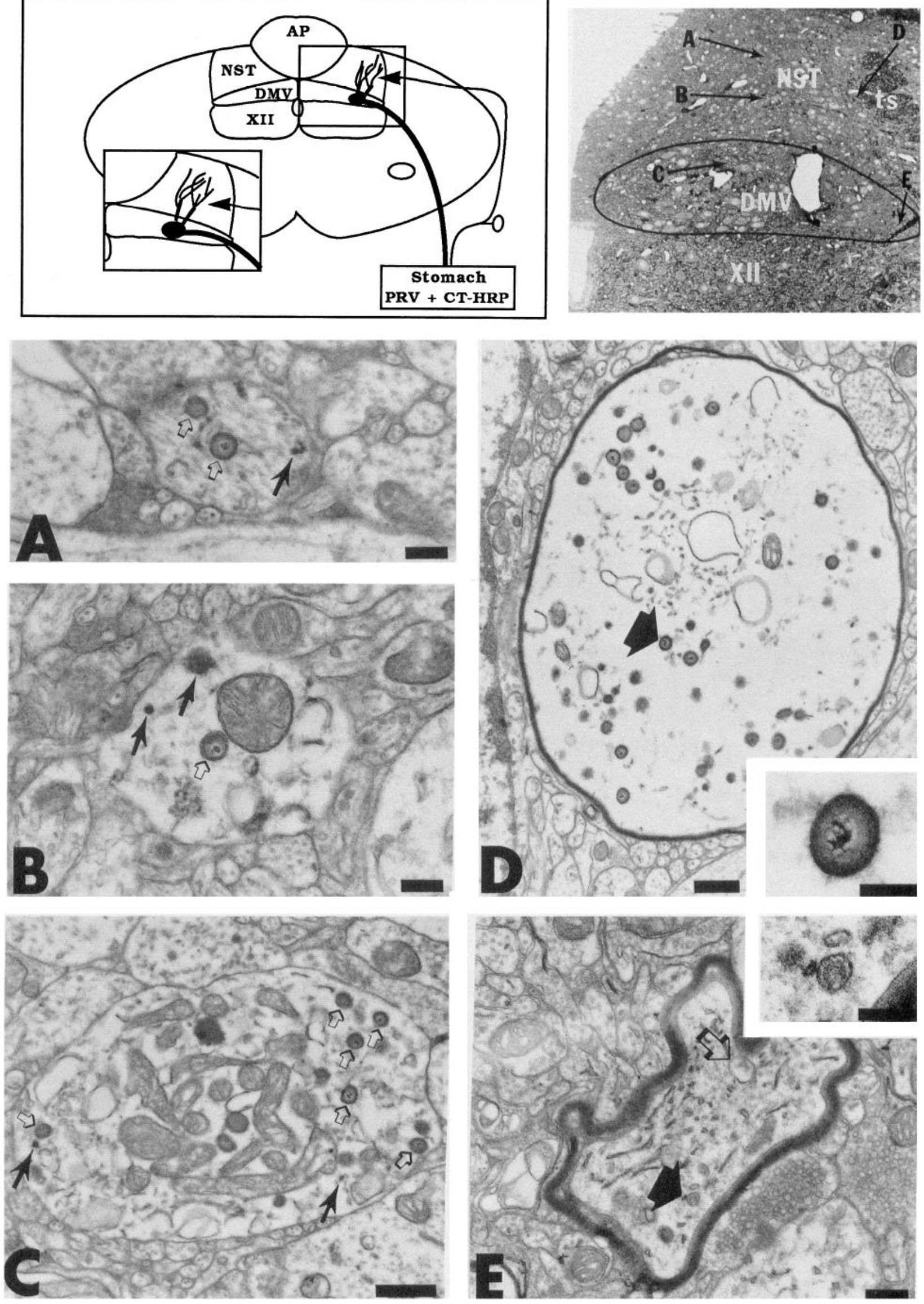

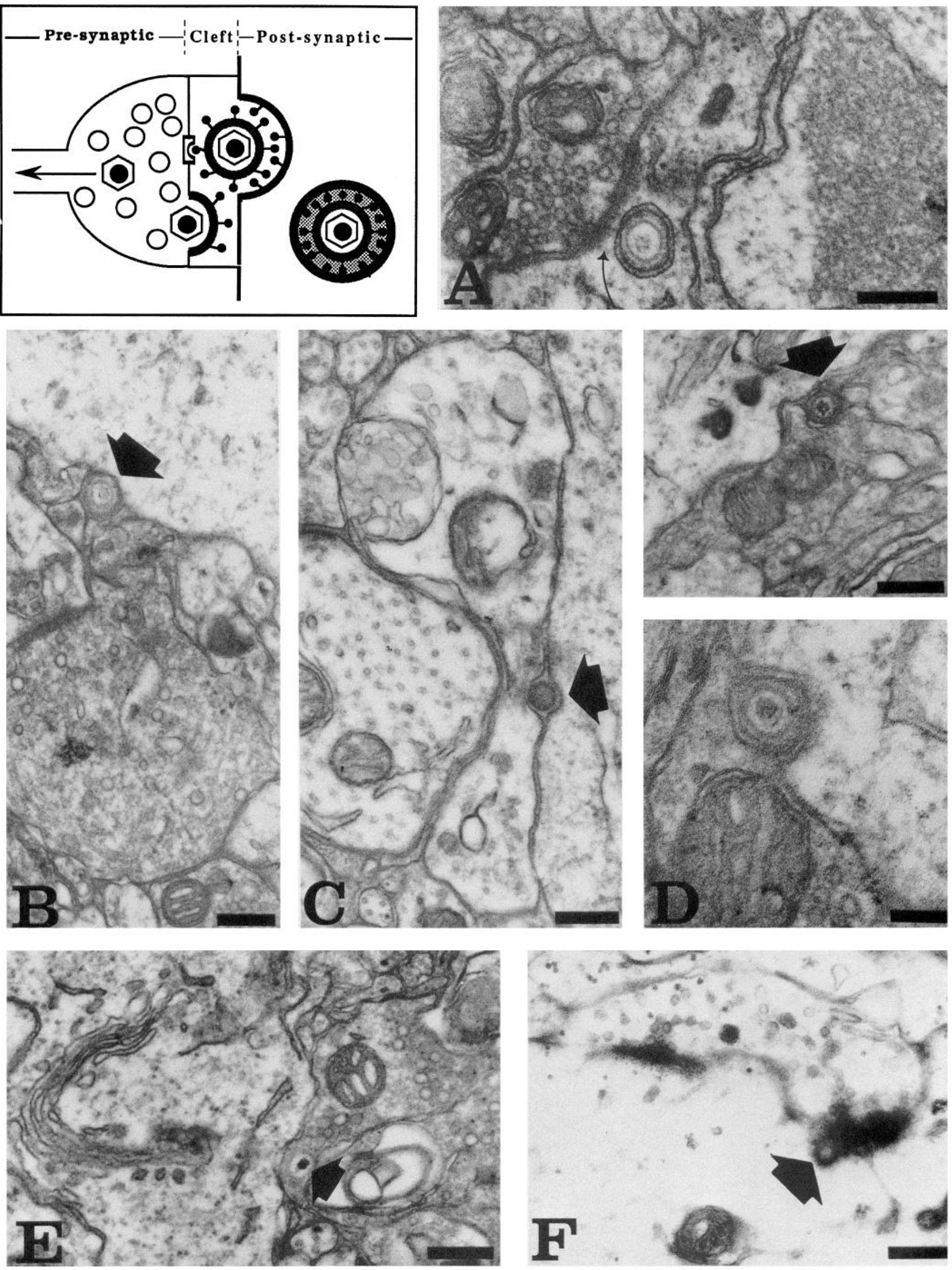

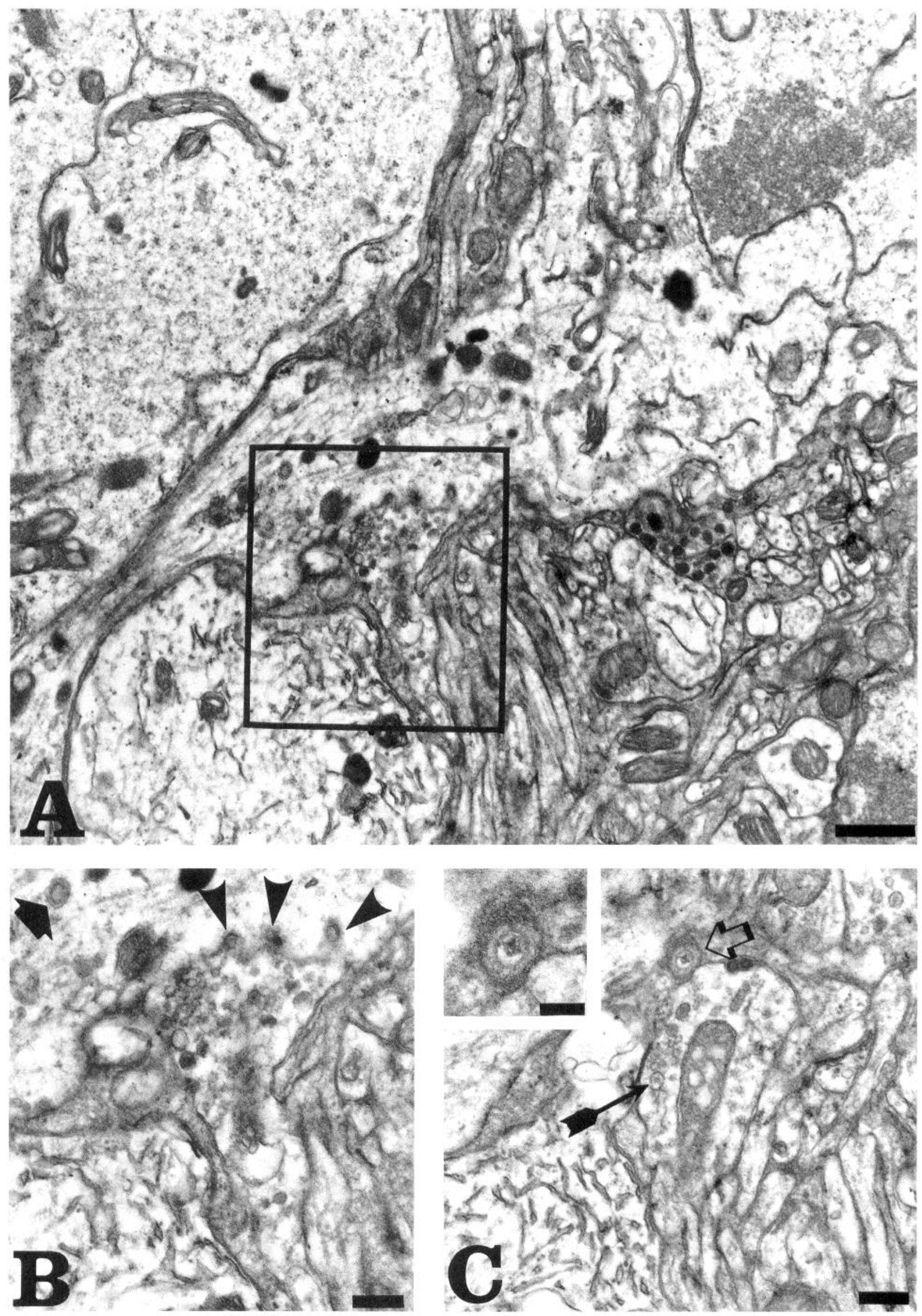


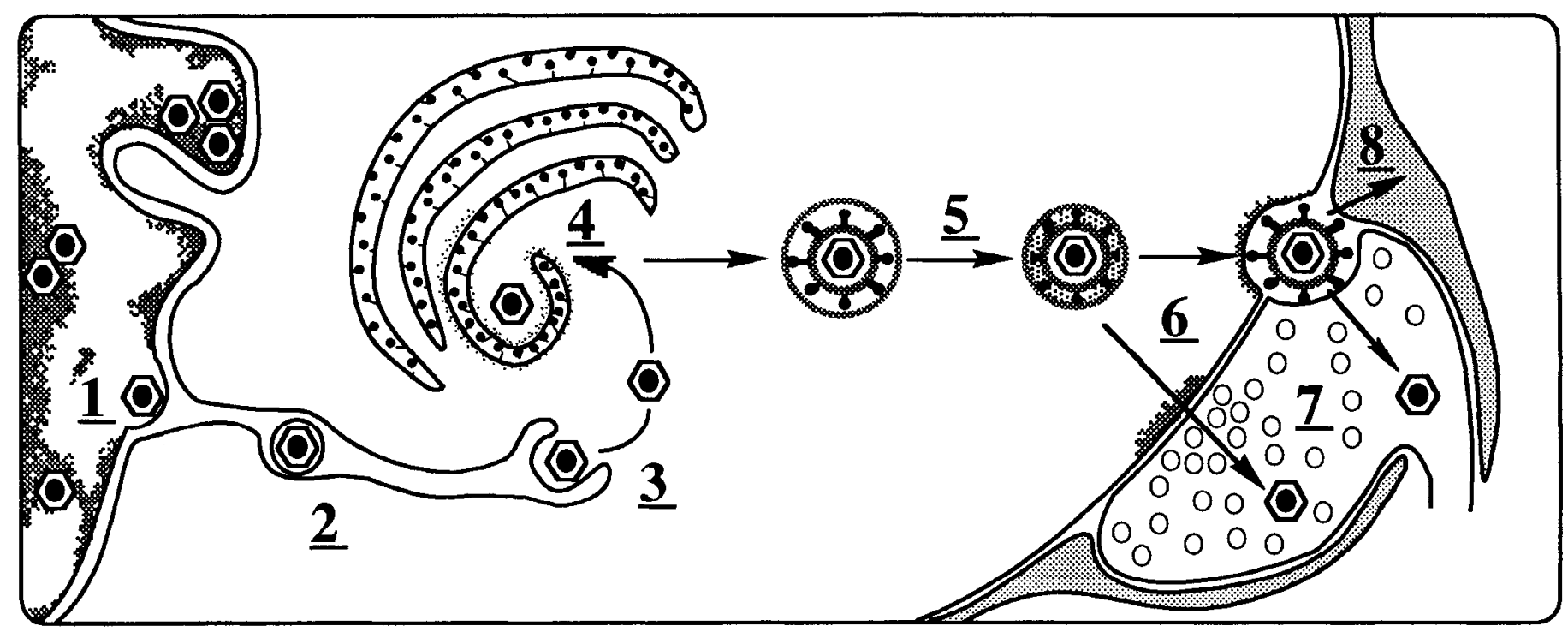

Figure 9. This schematic diagram summarizes the significant events (denoted by numbers) that lead to replication and transneuronal passage of PRV. Virions replicate in the cell nucleus, acquire a single membrane envelope at the inner leaf of the nuclear envelope (1), traverse the ER (2), and are released into the cytoplasm hy a fusion event between the virion membrane and the ER (3). The final envelope is applied to the capsid at the Golgi apparatus (4), endowing the virion with a bilaminar envelope derived from trans cisternae. The envelope of the virion consolidates and becomes more dense as the virion moves through the cell toward sites of afferent synaptic contact (5). Transneuronal passage of virus occurs by fusion of the outer membrane of the virion envelope with the postsynaptic membrane, releasing a single enveloped virion adjacent to the afferent (6). The remaining membrane of extracellular virions fuses with the membrane of the afferent to release the capsid into the afferent terminal (7), or may fuse with reactive astrocyte processes and infect these cells. Capsids released into afferent terminals are retrogradely transported to the parent neuron. Capsids that enter astrocytes lead to replication of viral DNA, but these cells are incapable of producing infectious virus.

the two animals infected with virulent strains of PRV. The morphology (Milligan et al., 1991; Rinaman et al., 1991) and ultrastructural characteristics (Streit et al., 1988; Kaur and Ling, 1992) of these cells were consistent with those described in the injured CNS. The cells characteristically contained a small oblong nucleus with clumped heterochromatin around the inner surface of the nuclear envelope. The cytoplasm exhibited a homogeneous granularity, active Golgi profiles, long linear arrays of rough ER, and numerous dense phagocytic inclusions (Fig. $11 A$ ). Thick branching processes emanated from the perikarya and surrounded afflicted neuronal profiles in the neuropil (Fig. $11 \mathrm{~A}$ ). These processes isolated infected neuronal profiles and phagocytosed cellular debris (Fig. $11 A-C$ ). However, even though microglia were intimately associated with infected neurons and their processes, they never contained virions or exhibited any morphological sign of infection.

Monocytes/macrophages. One of the principal hallmarks of advanced viral infection was an alteration in the morphology of the vasculature. Blood vessels in and immediately surrounding the infected DMV exhibited a distended perivascular space and a thickened appearance due to the accumulation of small osmophilic cells (Fig. $1 C, D$; inset Fig. 12). Cells of similar morphology were also present in the surrounding neuropil, especially in relation to neurons exhibiting the most pronounced pathology. The changes in vascular morphology were characteristic of all animals infected with virulcnt strains of PRV, but were not apparent in the animal infected with the attenuated virus. Ultrastructural examination of pathological blood vessels in animals infected with virulent PRV revealed that the small osmophilic cells exhibited morphological characteristics of monocytes and tissue macrophages. In several instances we found areas in which cells of monocyte morphology remained adherent to the inner surface of blood vessels, in spite of intravascular infusion of fixative at death (Fig. 12). Analysis of serial sections through these regions demonstrated that processes emanating from these cells contacted the luminal surface of the endothelium. These small spherical to slightly oblong cells were 5-8 $\mu \mathrm{m}$ in widest diameter, contained a dense organelle poor cytoplasm, and exhibited a spherical nucleus with dense marginated chromatin and few invaginations (Fig. 12). Cells of similar, but distinct, morphology were present in the distended perivascular space. These cells were more oblong in appearance, exhibited a lobulated cell nucleus, and contained a richer complement of cellular organelles and inclusions than the cells located in the blood vessels (Fig. 12).

Small osmophilic cells were also present in the neuropil of the DMV, especially in relation to neurons exhibiting advanced degenerative changes (Fig. 13A). However, these cells differed from those in the perivascular space in three important respects. First, they were more irregular in conformation and gave rise to processes that extended into the adjacent neuropil. Second, they contained a multilobulated nucleus and a large collection

Figure 10. A illustrates the perikaryon of an infected astrocyte that is in direct contact with the soma of an infected DMV motor neuron. Nucleocapsids are present in the cell nucleus, both individually and in aggregations (arrow). The boxed areas are illustrated at higher magnification in $B$ and $D . C$ is from another astrocyte in the same sample. Capsids surrounded by a single membrane are found within the distended profiles of ER $(B)$. The limiting membranes of these virions fuse with the ER to release naked capsids into the cytoplasm (arrows in $C$ ); the point of fusion is demarcated by the spiked coat that is characteristically present on the surface of the virions (large arrow in $C$ ). Capsids released from the ER accumulate within the cytoplasm and never acquire a final envelope $(D)$. Scale bars: $A, 1 \mu \mathrm{m} ; B-D, 200 \mathrm{~nm}$. 

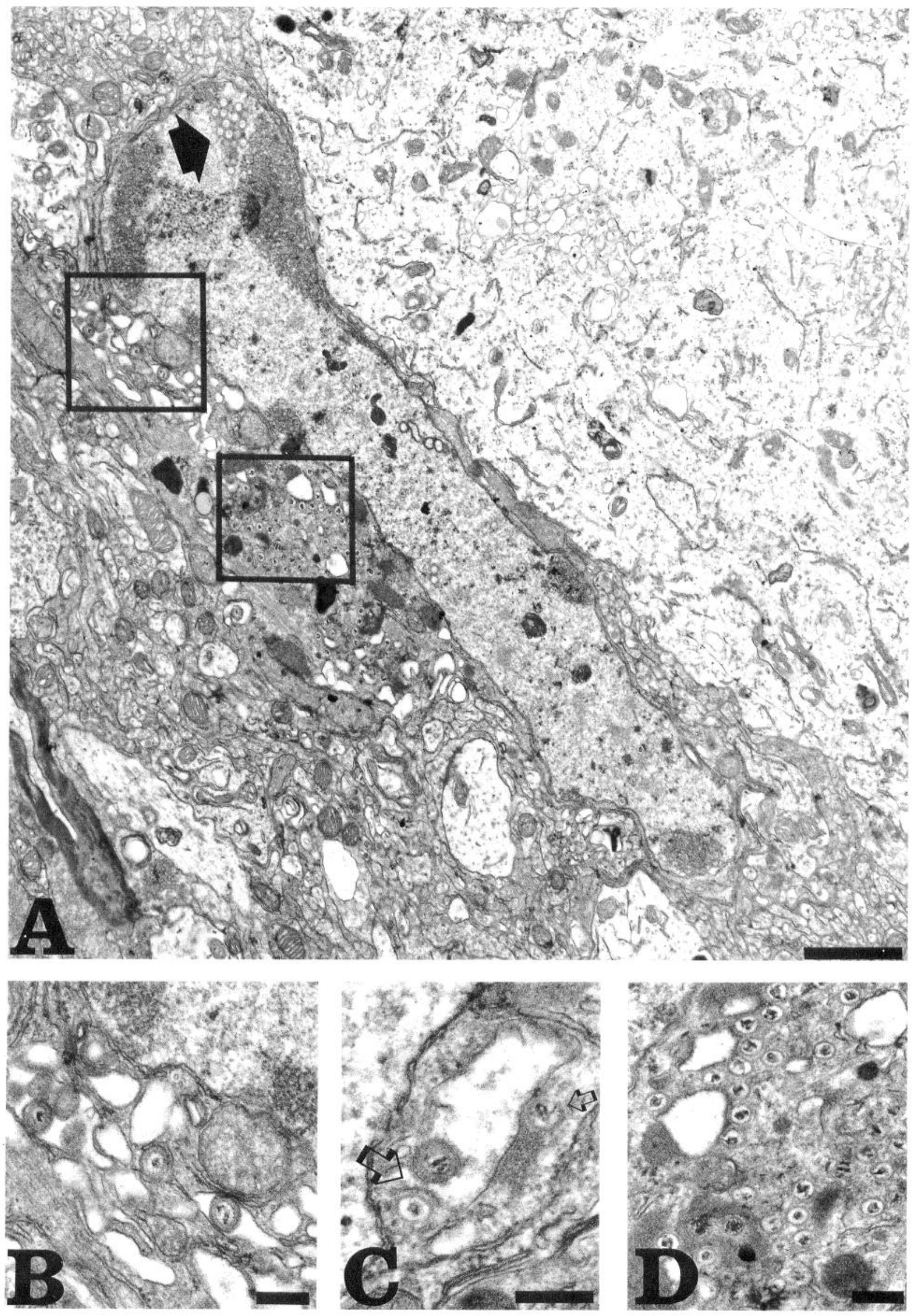

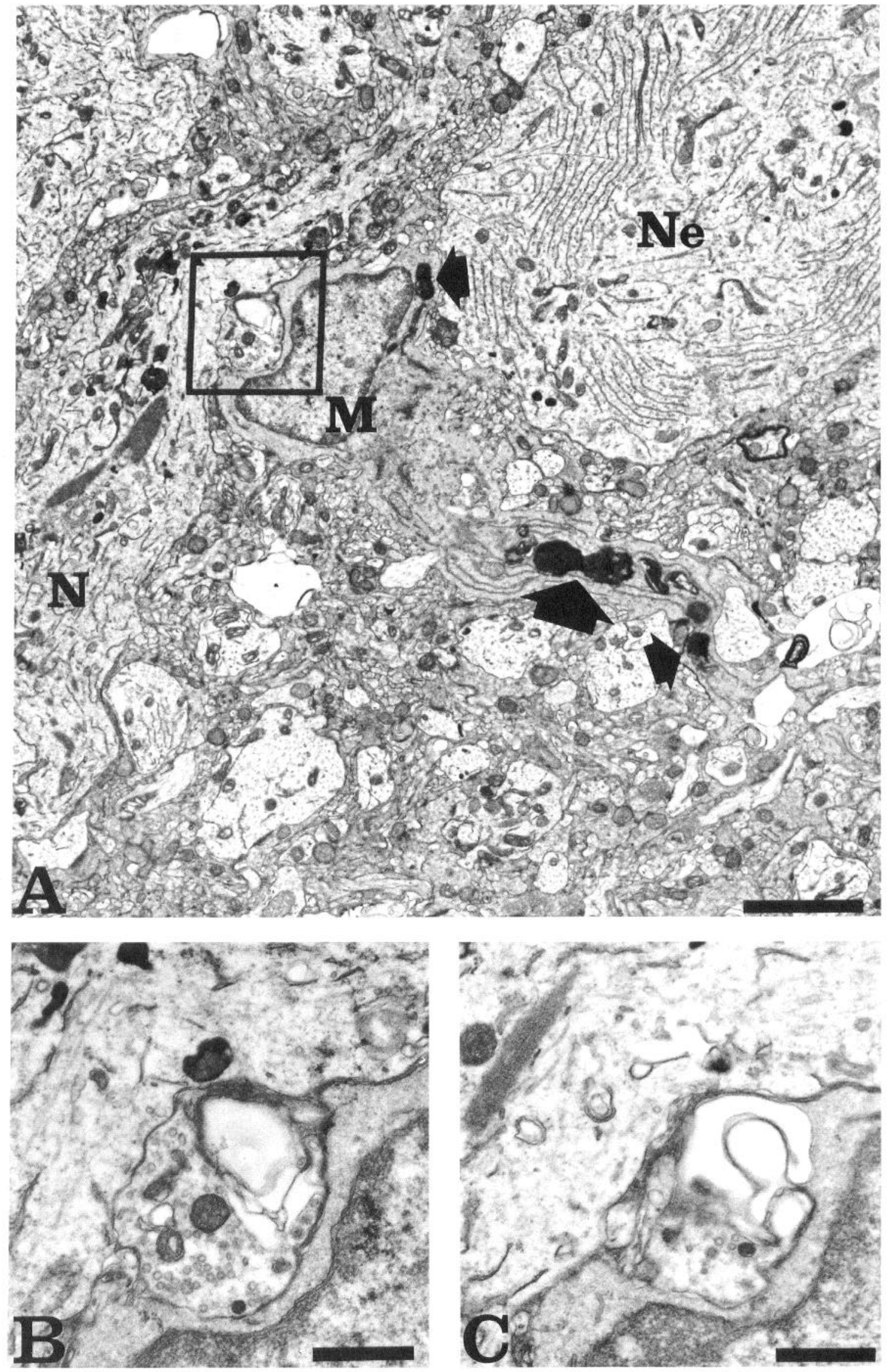

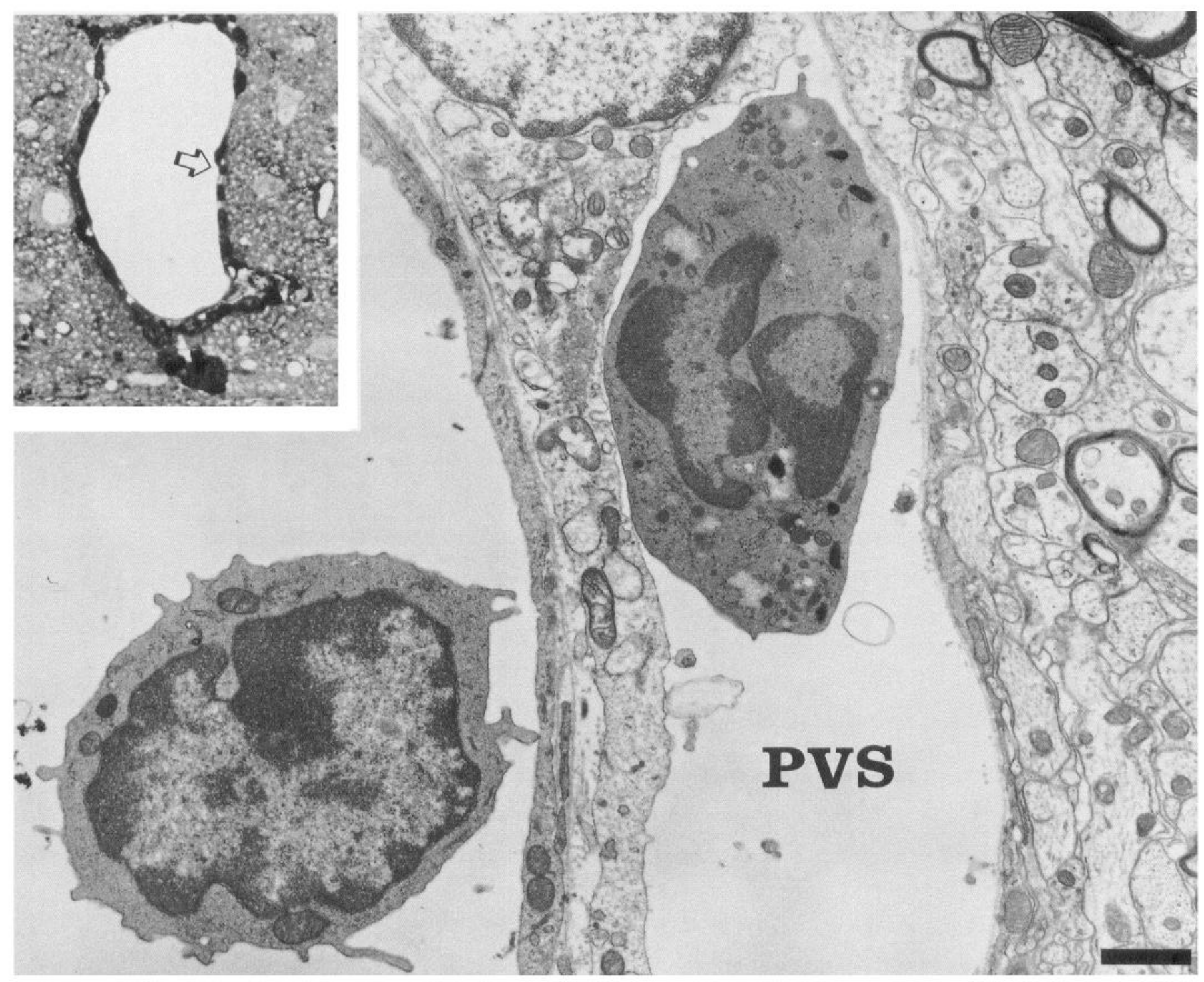

Figure 12. The vascular pathology that develops in response to infection of neurons with virulent strains of PRV is illustrated. The inset illustrates a large vessel in the DMV from an animal infected with PRV-4 $53 \mathrm{hr}$ prior to death. Note the thickened appearance of the vessel wall. The electron micrograph is from an ultrathin section adjacent to the area indicated by the arrow in the inset. The small spherical cell on the luminal side of the vessel exhibits ultrastructural features classically associated with monocytes. The dense cell in the perivascular space $(P V S)$ is similar in morphology, but contains a lobulated nucleus and a larger collection of organelles and cytoplasmic inclusions. Dense packing of these cells in the perivascular space accounts for the thickened appearance of the vascular wall in thick plastic sections (inset). Scale bar, $1 \mu \mathrm{m}$.

of electron-dense lysosomal bodies in the cytoplasm. Finally, they contained many large phagocytic inclusions and were intimately associated with neurons in advanced stages of degeneration. Often it appeared as if they were actually embedded within the degenerating cell (Fig. 13A). However, they did not exhibit signs of viral infection or pathology.

\section{Discussion}

Our data, summarized in Figures 9 and 14, support the conclusion that pseudorabies virus replicates within synaptically linked populations of neurons and that glia and macrophages restrict the spread of virus from infected neurons that become compromised. This conclusion is based upon transmission electron microscopic (TEM) analysis of DMV neurons infected with virulent or attenuated strains of PRV and our previous light microscopic analyses of the transport of these strains in the CNS (Card et al., 1990, 1991, 1992; Rinaman et al., 1993). Our earlier studies of PRV transport over longer survival intervals demonstrated that virus moves through the CNS in a circuit-specific fashion and does not produce the widespread necrotizing pat-

Figure 11. A illustrates a ramified microglial cell in association with two infected DMV motor neurons. The cell exhibits the dense cytoplasm, active Golgi bodies, and linear stretches of rough ER typically associated with these cells. Large phagocytic inclusions are also evident in the cell body and processes (arrows). The boxed area is illustrated at higher magnification in $B$ and in another plane of section in $C$. These micrographs reveal that the microglial cell is actively phagocytosing a degenerating afferent that terminates on a dendrite arising from an infected neuron $(N)$. $N e$, neuron; $M$, microglial cell. Scale bars: $A, 2 \mu \mathrm{m} ; B$ and $C, 500 \mathrm{~nm}$. 

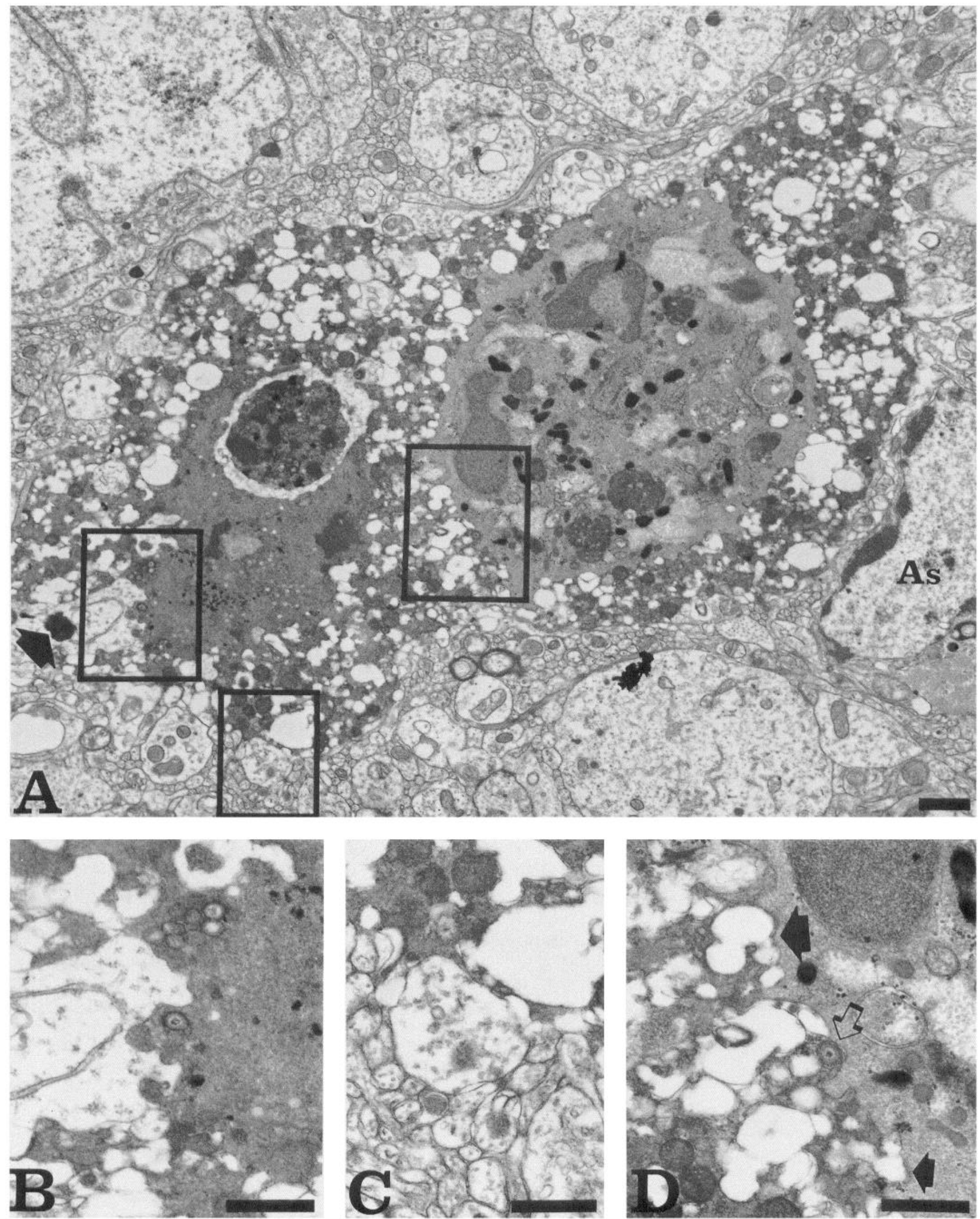

Figure 13. A DMV motor neuron exhibiting advanced dense vesicular degeneration is illustrated in $A$. The animal was infected with PRV-4 53 hr prior to death. The boxed areas are illustrated at higher magnification in $B-D$. In spite of the advanced pathology, the integrity of the neuron is maintained, and an afferent is still in contact with the cell soma $(C)$. Also, note the intimate association of a tissue macrophage and a reactive 
terns of infection that one would expect if it were spreading indiscriminately through the extracellular space or by cell fusion. However, other studies have shown that more virulent strains of PRV and HSV sometimes produce neuropathology that obviously reflects nonspecific spread of virus (Norgren and Lehman, 1989; Strack and Lowey, 1990). Thus, it is clear that our findings cannot be generalized for all $\alpha$-herpesvirus strains, and that analysis of viral transport within a well-defined temporal window is essential for appropriate interpretation of circuit related transport of virus. Nevertheless, our data provide unique insights into the processes of replication and dissemination of well-characterized strains of PRV that are widely used for neuronal tract tracing, and also provide valuable insights into the response of the CNS to viral infection.

It can be argued that electron microscopy is ill suited for making assertions about the temporal aspects of viral replication and transport in the CNS. The labor intensive nature of the method and the small sample size that can be effectively examined present formidable barriers to this type of analysis. For example, it is always possible that the failure to observe nonspecific release of virus into the extracellular space is due to the restricted sampling inherent to the method. We have taken the following measures to address these considerations. First, we are using a system in which the neuronal architecture, connections, and response to viral infection are well characterized. The polarized dendritic tree of DMV neurons (Shapiro and Miselis, 1985) and its well-described connections with vagal sensory afferents (Rinaman et al., 1989) and NST neurons (Pickel et al., 1989) present an ideal system for examining assembly and transneuronal passage of virus. Furthermore, we have previously characterized the transport of both the Becker and Bartha strains of PRV through this circuitry (Card et al., 1990; Miselis et al., 1991; Sternini et al., 1991; Rinaman et al., 1993). Second, we processed animals for light microscopic immunohistochemical analysis in parallel with those processed for TEM using the same experimental parametrics and reagents. Conscquently, we were able to gauge the relative transport of each of the threc strains of PRV. Third, we standardized our analysis to the region of the DMV either immediately rostral to or at the level of the area postrema to reduce any variability in viral transport that might occur because of the viscerotopic organization of the DMV/ NST complex (Shapiro and Miselis, 1985; Rinaman and Miselis, 1987; Altschuler et al., 1991). Fourth, we conducted a rigorous light microscopic analysis of thick sections immediately adjacent to areas subjected to ultrastructural examination in order to document our TEM analysis thoroughly and ensure that all areas of pathology were analyzed. Fifth, many of the profiles were examined in serial ultrathin sections. We routinely cut repeating series of 2-10 consecutive ultrathin sections of tissue infected with virulent strains of PRV, and over 1500 consecutive sections were cut through the DMV of the animal infected with the attenuated strain. Sixth, the systematic fashion in which the TEM analysis was conducted ensured thorough sampling of the entire DMV/NST complex and identification of all infected profiles. Seventh, we used an electron-dense tracer (CT-HRP) to help us identify both the motor and sensory components of the vagal innervation of the stomach that were infected with virus. Finally, examination of multiple infected cells in each sample, as well as the use of virulent and attenuated strains of virus, permitted us to analyze cells in all stages of viral infection. Collectively, this approach provided us with an accurate means of assessing both the intracellular pathways of viral replication and egress as well as the the non-neuronal response to viral infection of neurons.

We observed three basic stages in the CNS in response to PRV infection. The first stage was manifested by capsid replication in the cell nucleus and the appearance of virions in lysosomes. Lysosomal inclusions containing virions in various stages of degradation were demonstrable early in the course of cellular infection, but there was not a dramatic increase in the number of these inclusions in neurons exhibiting more advanced pathology. This suggests that the initial response of afflicted cells was to shunt newly replicated virions to lysosomes and that this response was ultimately overwhelmed as the infection progressed. The second stage involved productive replication and specific egress of infectious virus. The directed assembly and intracellular transport of virions in this phase led to transneuronal passage of virus at sites of afferent synaptic contact. In the third phase, infected neurons began to succumb to the infection and a non-neuronal response was mounted that limited the spread of virus from compromised neurons.

\section{Virion replication and assembly}

Replication and assembly of $\alpha$-herpesviruses is a complex multistep phenomenon that begins with viral DNA replication in the nucleus and ends with the application of a membrane envelope (see Roizman and Sears, 1990, for a review). The precise intracellular route of assembly is controversial, and a number of sites of capsid envelopment have been proposed. The results of the present investigation are consistent with those revealed in our previous in vitro analysis of PRV replication in immortalized pig kidney fibroblasts (Whealy et al., 1991) and also contain elements of models proposed for other herpesviruses (Stackpole, 1969; Johnson and Spear, 1982, 1983; Jones and Grose, 1988; Komuro et al., 1989). We found that, following viral DNA replication and packaging in the cell nucleus, nucleocapsids acquired a single membrane envelope by budding through the inner leaf of the nuclear membrane. These membrane limited capsids then traversed the ER and were released into the cytoplasm by a fusion event in which the limiting membrane of the virion fused with the ER. Final envelopment occurred at the Golgi apparatus where a bilaminar membrane derived from trans cisternae was applied to the capsid (Fig. 9).

Capsid assembly. The structural organization of the icosahedral structural protein capsid enclosing viral DNA is well characterized, but the individual events leading to its assembly in the cell nucleus remain elusive. Our data suggest that the complex array of 10-15 $\mathrm{nm}$ tubules that formed focal aggregations in the nuclei of infected neurons may be involved in mobilization of the protein constituents of the capsid to focal

astrocyte $(A s)$ with the degenerating neuron in $A$. The macrophage contains several prominent phagosomes (open arrows), but shows no morphological indications of infection or degenerative pathology. There are numerous sites at which vesiculation in the neuron appears to be related to release of a cytotoxic substance from the macrophage (arrow in $D$ ). $B$ shows a portion of the degenerating neuron being phagocytosed by a protoplasmic astrocyte that contains a prominent phagosome (arrow in $A$ ). Capsids and enveloped virions are prominent throughout the cytoplasm of the degenerating neuron ( $B$ and arrow in $D$ ). Scale bars: $A, 1 \mu \mathrm{m} ; B-D, 500 \mathrm{~nm}$. 

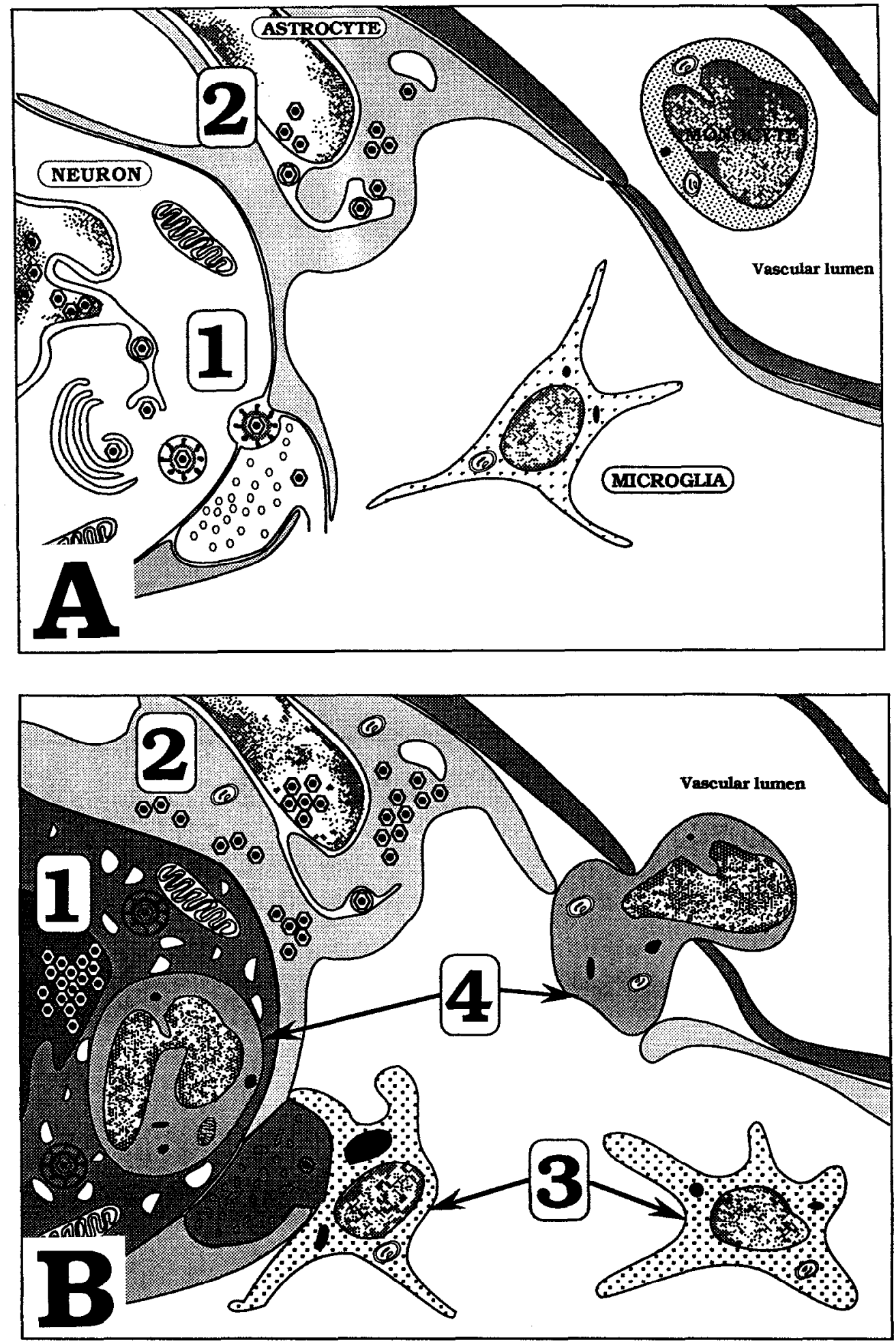

Figure 14. The response of glia and macrophages early $(A)$ and late $(B)$ in the course of neuronal infection with PRV are illustrated. $A$ (early response), Viral replication and assembly in neurons ( 1 ) leads to reactive astrogliosis that isolates infected neurons and the afferent axon terminals that synapse upon them (2). Microglia and macrophages show very little response at this stage. $B$ (late response), Neurons advanced in the course of infection exhibit dense degeneration ( 1 , and the astroglial response becomes more pronounced (2). Microglial cells increase in size and density in the vicinity of these cells and phagocytose degenerating neurons and processes (3). Monocytes leave the vasculature at the site of infection, differentiate into tissue macrophages, and become intimately associated with the degenerating neurons (4).

sites in the nucleus for assembly. These proteins are synthesized in the cytoplasm of the cell and must find their way back into the cell nucleus to assemble and encapsulatc viral DNA. Our data demonstrate that these tubules often form circular arrays around coalescing viral DNA in the nuclei of infected cells. This morphological association, along with the observation that capsids in various stages of assembly were routinely enmeshed in these tubular arrays, leads us to hypothesize that the intranuclear 
tubule masses support efficient assembly of capsids by transporting structural proteins to assembly sites and/or providing a "scaffolding" for capsid assembly. However, further analysis is necessary to determine the validity of this hypothesis.

Envelopment. Previous in vitro studies of HSV and varicella zoster virus have proposed that application of the viral cn velope to nucleocapsids occurs at the nuclear envelope (Johnson and Spear, 1982), by migration of immature particles through the Golgi cisternae (Johnson and Spear, 1983), or by budding of capsids into Golgi-derived vesicles for bulk transport to the cell membrane (Jones and Grose, 1988). Studics of PRV replication have also proposed a variety of sites for virion envelopment. McCracken and Clarke (1971) suggested that capsids acquire an envelope from the inner and outer nuclear membranes, smooth and rough endoplasmic reticulum, and the Golgi complex. Pol et al. (1991 b) studied three strains of PRV (including the Bartha strain used in the present analysis) and concluded that there were differences in the sites that virulent and attenuated strains were enveloped. They reported that only virulent strains acquired an envelope at the nuclear membrane and further suggested that the failure of the Bartha strain to be enveloped at this site was due to the absence of the gene that encodes the gI viral envelope glycoprotein. In contrast, our data demonstrate a common mode of envelopment for both virulent and attenuated strains of PRV. All of the events associated with assembly of the two virulent strains also occurred in the assembly of the Bartha strain, which lacks the gI gene. Thus, our observations do not support the conclusion that the gI gene must be present for capsids to acquire a membrane at the nuclear envelope as suggested by Pol et al. (1991b). However, it remains possible that this inconsistency is related to the different cell types (nasal mucosa vs. pig kidney fibroblasts and neurons) used in these studies.

Our model of assembly contains many of the elements observed in previous studies, but we interpret thesc events as part of a larger pathway of assembly that ultimately leads to final envelopment of capsids at the trans face of the Golgi. A critical considcration in this model is that capsid envelopment at the inner membrane of the cell nucleus provides a means of transporting capsids from the cell nucleus to the cytoplasm, and does not reflect final envelopment of the virion. This hypothesis has also been advanced by Lycke et al. in their in vitro analysis of HSV assembly in human dorsal root ganglia sensory neurons (Lycke et al., 1988) and is supported by a recent in vitro analysis of the role of viral envelope glycoproteins in PRV replication and egress (Peeters et al., 1992). Lycke et al. (1988) demonstrated capsids budding through the inner leaf of the membrane and further postulated that fusion of this membrane with the outer leaf of the nuclear envelope was an "essential step" in providing capsids access to the cytoplasm. Peeters et al. (1992) demonstrated that capsids produced by mutant strains of PRV, lacking the gene for envelope glycoprotein gII, bud through the inner leaf of the nuclear membrane, but are incapable of fusing with the outer leaf. Thus, virions accumulate within the perinuclear space, and infectious virus is never produced by the cell. These data support the contention that membrane acquisition at the nuclear envelope simply provides nuclcocapsids with a means of gaining access to the cytoplasm via the ER.

The data from this and our previous investigation (Whealy et al., 1991) indicate that the final envelope applied to newly replicated virions is derived from the trans face of the Golgi. Other investigations of $\alpha$-herpesvirus envelopment have sug- gested that the viral envelope is acquired either directly at the Golgi (Dubois-Dalcq et al., 1982; Komuro et al., 1989) or from Golgi-derived vesicles (Stackpole, 1969; Johnson and Grose, 1988). Processing and packaging of glycoproteins, differential sorting of vesicles among cellular compartments, and membrane recycling are all essential functions of the Golgi (for recent reviews, see Geuze and Morre, 1991; Mollenhauer and Morre, 1991; Morre, 1991; Mellman and Simons, 1992) that are required for appropriate virion assembly and egress. While our findings support the conclusion that the viral envelope is acquired directly from the Golgi cisternae, we cannot exclude the possibility that capsids bud into Golgi-derived vesicles adjacent to this organelle. Nevertheless, either mechanism of envelopment incorporates the normal functional properties of the Golgi apparatus as an efficient means of endowing the capsid with an envelope that contains mature glycoproteins, and also provides a mechanism of supplying the virus with targeting signals that would allow differential sorting of newly wrapped virions to specific areas of the cell (i.e., dendrites vs. axon).

\section{Intracellular targeting and egress of virions}

One of the early signs of viral infection in DMV motor neurons included pathological invaginations of cell nuclei and the accumulation of degrading virions in lysosomes. The analysis of serial ultrathin sections conducted on the PRV-Ba-infected sample revealed that individual lysosomes were generally part of a larger group that were interconnected by narrow dense tubules. These chains of variable sized varicosities are very similar to the continuous endosomal reticulum described by Hopkins et al. (1990) and were most prevalent at the peripheral aspects of the cell soma and in the proximal portions of primary dendrites. They appeared early in the course of infection, but their numbers did not increase dramatically with advancing viral replication. This suggests that their appearance may have been the product of an initial attempt of the cell to protect itself from viral infection by targeting newly replicated virions to lysosomes for degradation, and that this response was subsequently overcome with advancing viral replication. We also observed a spiked coat on the portion of the trans cisternae that wrapped capsids that was similar in morphology to the clathrin coat applied to Golgi-derived vesicles sorted to lysosomes (see review by Mcllman and Simons, 1992). This coat was also observed on the outer membrane of virions fusing with lysosomes. With the available data we are unable to make an absolute correlation of the occurrence of this coat with a particular stage of infection. We can say that it was routinely observed on the trans Golgi cisternae of cells exhibiting early morphological signs of infection and that it was more difficult to demonstrate in cells with advanced pathology. However, a more systematic examination of cells in various stages of infection is required to support the assertion that the presence of this coat is correlated with sorting of virions to lysosomes.

There was no evidence in our material that lysosomal inclusions or fusion of infected cells contributed to dissemination of virus in the CNS. Lysosomal inclusions filled with virions were confined to the soma and primary dendrites of infected cells, and we never observed any of these large inclusion bodics fusing with the plasma membrane to release virions into the extracellular space. Similarly, we observed many cases in which infected neurons and glia were in direct apposition, but there was never any evidence that these cells had fused. Thus, the in vitro demonstration of virus-induced cell fusion (reviewed by Spear, 1984) 
does not appear to be relevant to spread of PRV through the CNS. This observation is consistent with the many studies that have shown that $\alpha$-herpesviruses generally pass through the nervous system in a circuit-specific fashion rather than via lateral spread.

It is our impression that the morphology of virions destined for release from infected neurons differed from those targeted to lysosomes. This conclusion is supported by our analysis of virion morphology in the perikarya and processes of DMV motor neurons as well as the early in vitro studies of $\alpha$-herpesvirus assembly and egress (Morgan ct al., 1959; Nii ct al., 1968a,b; McCracken and Clarke, 1971; Fong et al., 1973). Fong ct al. (1973), in particular, noted that the envelope morphology of guinea pig herpes-like particles varied "depending upon the location of the virus" in the cell. In our analysis, virions associated with lysosomes characteristically exhibited membrane decorations on the outer surface of the external membrane, whereas virions in the dendritic tree were more spherical and slightly smaller (approximately $180 \mathrm{~nm}$ ), and the envelope was of greater density and smoother conformation. Our data also demonstrated that axons of infected motor neurons only contained free capsids, whereas virions endowed with a double membrane envelope were differentially concentrated in the somata and dendrites. These data confirm the elegant in vitro findings of Lycke et al. (1988) and Marchand and Schwab (1986), who demonstrated that viral DNA was retrogradely transported to neuronal perikarya in free capsids, and that double-enveloped virions only appeared in the perikarya and processes after viral replication had occurred. The differential intracellular distribution of enveloped virions is also consistent with the demonstration that viral glycoproteins are sorted to the dendrites of cultured hippocampal neurons (Dotti and Simmons, 1992). Collectively, these findings indicate that the differential intracellular distribution of morphologically distinct virions recognized in earlier in vitro studies is even more apparent in the highly polarized cellular compartments of neurons, and that the structural features of virions in different ccllular compartments provide clear morphological correlates of events that occur during viral entry, replication, and egress.

Although release sites always occurred adjacent to afferent terminals, the precise site of virion egress was not always into the synaptic cleft (see summary, Fig. 9). The critical cvent in relcase was fusion of the outer membrane of the virion envelope with the postsynaptic membrane of the infected cell. A second fusion event between the remaining membrane of the viral envelope and the membrane of the afferent terminal then released the naked capsid into the afferent. These observations are consistent with previous studics that have demonstrated that a membrane is necessary for both release of infectious virus as well as viral invasion of another cell (see Nii et al., 1968a, for discussion). However, it should be noted that the topology of the viral glycoproteins in the outer membrane of this bilaminar envelope is such that the cytoplasmic domains are on the outside. Thus, fusion of this membrane with the host plasma membrane releases a virion in which envelope glycoproteins are in the proper conformation necessary for performing their functions in recognition, attachment, and invasion of susceptible cells. In contrast, the initial fusion event that releases the virion from the cell involves a membrane in which these glycoproteins are in the opposite conformation.

The mechanism(s) that would confer specificity on the intracellular targeting of virions to postsynaptic membranes has not been elucidated. Our data strongly support the conclusion that newly assembled virions are differentially targeted to the dendritic tree of infected central neurons and are specifically released at sites of afferent contact. This observation is consistent with mapping studies that have shown that PRV travels through CNS is dependent upon a gene designated ${ }_{, 1}$ 34.5. Deletion of et al., 1990; Strack and Loewy, 1990; Miselis et al., 1991; Sternini et al., 1991; Jansen et al., 1992; Rotto-Percelay, 1992). However, the mechanisms involved in virion fusion with afferent terminals following release from infected ncurons require further definition. It has not been established that fusion of virions with afferent terminals is a specific event or merely the product of reuptake processes such as those that permit HRP, latex microspheres, and other retrograde tracers to gain access to axon terminals (Kristensson and Olsen, 1971; LaVail and LaVail, 1973; Katz et al., 1984; Schmued and Fallon, 1986). A substantial literature supports the conclusion that $\alpha$-herpesvirus invasion of cells is a receptor-mediated event involving viral glycoproteins and an as yet uncharacterized receptor (Spear, 1984; Roizman and Sears, 1990). However, these conclusions are based primarily upon in vitro investigations of a variety of cell lines, and do not consider the relatively "nonspecific" uptake mechanisms that permit latex microspheres to gain access to axons. Consequently, it remains possible that specific transneuronal passage of virus is dependent upon the ability of neurons to sort virions differentially to specific areas of the cell (i.e., the postsynaptic membrane), and that viral uptake at afferent terminals is a relatively nonspecific, secondary event. Further analysis of the uptake and transport of viral mutants lacking glycoproteins shown to be essential for invasion of cells in vitro is necessary to address this question.

\section{Neuropathogenesis}

There is little doubt that infection of ncurons with PRV ultimately leads to cell death. This response is most evident in neurons infected with virulent strains of virus, but also occurs in neurons infected with attenuated strains after prolonged viral replication (Card et al., 1992). The fundamental mechanisms underlying this response have not been fully characterized, but available evidence suggests that the virally induced cytopathogenesis may occur in response to expression of gene products encoded by the virus as well as via the ncuroimmune response elicited by viral infection. Chou et al. (1990) have recently shown that the ability of HSV- 1 to induce lethal infection of the mouse CNS is dependent upon a gene designated ${ }_{\gamma 1}$ 34.5. Deletion of the two copics of this gene or insertion of stop codons produces strains of HSV that are avirulent following intracerebral inoculation. It is not yet known whether PRV contains a similar gene, but a number of recent studies have demonstrated a reduction in neurovirulence following deletion of genes that encode PRV envelope glycoproteins (Ben-Porat and Kaplin, 1985; Card et al., 1992; Kimman et al., 1992; Zsak et al., 1992). Thus, at least some of the cytopathic effects observed in infected neurons may be duc to expression of virally encoded genes.

Viral infections have also been shown to elicit the expression of a variety of cytokines that may contribute, either directly or indirectly, to death of infected neurons. For example, interleukin-6 (Frci et al., 1989; Lieberman et al., 1989), tumor necrosis factor (TNF) (Lieberman et al., 1989), and interferons (Lieberman et al., 1989) are secreted by astrocytes in response to neurotropic viral infections. The expression of TNF under these circumstances is particularly intriguing in light of the di- 
verse role that this cytokine has been shown to play in neuroinflammatory responses of the CNS (Beutler and Cerami, 1989). In particular, our work has demonstrated that macrophages are prevalent in arcas of PRV-induced neuropathogenesis (see also Rinaman et al., 1993) and that these cells establish very intimate associations with neurons in advanced stages of degencration. Our data also suggest that these macrophages are derived from peripheral blood monocytes that migrate into the CNS and differentiate into tissue macrophages. Both of these observations are interesting in light of studies that have shown that astrocytes infected with neurotropic viruses secrete TNF (Lieberman et al., 1989), and that TNF is involved in macrophage differentiation (Witsell and Schook, 1992) and also induces expression of adhesion molecules by neurons (Birdsall et al., 1992). Our ultrastructural data revealed that macrophages were literally attached to the surface of necrotic neurons and may have contributed to the degenerative vesiculation that was so prevalent in these compromised neurons. This response is quite similar to the TNF-induced facilitation of mononuclear leukocyte adherence to human cortical neurons and neuroblastoma cells in response to expression of cellular adhesion molecules by these cells (Birdsall et al., 1992). In addition, Thery et al. (1991) recently demonstrated cytotoxic effects of brain macrophages on developing neurons. Collectively, these observations suggest a complex interaction of cytokines, adhesion molecules, and cytotoxic macrophages in virally induced pathogenesis.

\section{The role of glia in transneuronal passage of virus}

Three aspects of our findings suggest that glia play a prominent role in ensuring circuit-specific passage of virus through the CNS. First, our data support the conclusion that astrocytes and microglia respond to viral infection of neurons by undergoing a reactive gliosis that effectively isolates infected neurons and contributes to the removal of cellular debris. Second, the data from this and other investigations (Field and Hill, 1974; Bak ct al., 1977) indicate that astrocytes are susceptible to infection by PRV, but are incapable of releasing infectious virus. Thus, the astrocytic cells and processes that ensconce infected neurons provide a very effective barrier that limits spread of virus from sites of primary infection, irrespective of the pathological state of the afflicted neuron. Third, although microglia phagocytose infected neurons, they are resistant to PRV infection. When considered with the numerous reproducible demonstrations of unique, circuit-specific transport of virus in the CNS, these data strongly support the conclusion that the glial response to neuronal infection effectively limits nonspecific spread of virus.

Astrocytes are among the first cells to respond to PRV infection of neurons (Rinaman et al., 1993) and play a prominent role in restricting the spread of virus. Filament-rich processes of these cells were present on the surface of infected neurons, and their processes surrounded afferents synapsing on these cells. In many instances in which we observed release of virus at these sites of afferent contact, the released virion had equal access to either the afferent terminal or the surrounding astrocytic shcath (Fig. 14). Consequently, it is not surprising that astrocytes ultimately became infected, especially when one considers previous studies by Vahlne et al. $(1978,1980)$ that demonstrated astrocytic membranes to have a very high affinity for $\alpha$-herpesviruses. However, we were surprised to find that astrocytes harbored a defect that prevented envelopment of capsids in the cytoplasm. Previous studies (Field and Hill, 1974; Bak et al.,
1977) had commented on the absence of enveloped virions in satellite glia and astrocytes, but there was no clear indication that these cells harbored a replication defect. We observed capsid replication in the nuclei of infected astrocytes, and these capsids budded through the nuclear envelope and were transported to the cytoplasm via the ER in the same manner that occurred in neurons. However, rather than being enveloped, naked capsids accumulated in large aggregations in the astrocyte cytoplasm and enveloped virions were never obscrved in systematic examination of serial sections. The fundamental mechanism underlying this defect remains to be established, but the existence of a replication defect in astrocytes indicates that these cells act as a reservoir for virions that do not gain access to afferents and thereby limit indiscriminate spread of virus through the extracellular space.

Our data also support previous reports (Morahan, 1983; Morahan et al., 1985; Inglesias et al., 1989; Rinaman et al., 1993) demonstrating that different populations of glia are differentially susceptible to viral infection. Although microglia were prevalent throughout all of our preparations and werc intimately associated with neurons exhibiting advanced pathology, we never observed any evidence of viral infection in these cells. This is consistent with our previous light microscopic observations on the response of immunocytochemically identified ramified microglia to PRV infection (Rinaman et al., 1993) and the demonstration that microglia resist infection by HSV (Weinstein et al., 1990). Thus, the primary function of these cells appears to be phagocytosis of degenerating neurons.

\section{Conclusions}

Our findings suggest that spread of PRV through the CNS following peripheral inoculation occurs by retrograde transneuronal passage of virus through synaptically linked populations of neurons. The specificity of this transport is the product of a complex process of viral replication, assembly, and intracellular sorting that specifically targets newly replicated virions to sites of afferent synaptic contact on the cell soma and dendritic arbor. Glial cells and infiltrating macrophages also play a prominent role in maintaining the specificity of transneuronal passage. These cells act to isolate infected neuronal profiles and thereby prevent nonspecific dissemination of virus through the extracellular space. The potential for spread of virus through infected astrocytes is obviated by the inability of these cells to produce infectious virus. Thus, they act as a sink for virions that are released from necrotic neurons at advanced stages of infection.

\section{References}

Altschuler SM, Ferenci DA, Lynn RB, Miselis RR (1991) Representation of the cecum in the lateral dorsal motor nucleus of the vagus nerve and commissural subnucleus of the nucleus tractus solitarii in rat. J Comp Neurol 304:261-274.

Bak IJ, Markham CH, Cook ML, Stevens JG (1977) Intra-axonal transport of herpes simplex virus in the rat central nervous system. Brain Res 136:415-429.

Bak IJ, Markham CH, Cook ML, Stevens JG (1978) Ultrastructural and immunoperoxidase study of striatonigral neurons by means of retrograde axonal transport of herpes simplex virus. Brain Res 143: $361-368$.

Bartha A (1961) Experimental reduction of virulence of Aujeszky's disease. Magy Allatorv Lapja 16:42-45.

Becker CH (1967) Zur primaren Schadingung vegetativer Ganglien nach Infektion mit deme Herpes suis Virus bei verschiedenen Tierarten. Experentia 23:209-217.

Ben-Porat T, Kaplan AS (1985) Molecular biology of pseudorabies 
virus. In: The herpesviruses (Roizman B, ed), pp 105-173. New York: Plenum.

Beutler B, Cerami A (1989) The biology of cachectin/TNF-a primary mediator of the host response. Annu Rev Immunol 7:625-655.

Birdsall HH, Lane C, Ramser MN, Anderson DC. (1992) Induction of VCAM-1 and ICAM-1 on human neural cells and mechanisms of mononuclear leukocyte adherence. J Immunol 148:2717-2723.

Blessing WW, Li YW, Wesselingh SL (1991) Transneuronal transport of herpes simplex virus from the cervical vagus to brain neurons with axonal inputs to central vagal sensory nuclei in the rat. Neuroscience 42:261-274.

Card JP, Riley JN, Moore RY (1986) The motor trigeminal nucleus of the rat: analysis of neuronal structure and the synaptic organization of noradrenergic afferents. J Comp Neurol 250:469-484.

Card JP, Rinaman L, Schwaber JS, Miselis RR, Whealy ME, Robbins AK, Enquist LW (1990) Neurotropic properties of pseudorabies virus: uptake and transneuronal passage in the rat central nervous system. J Neurosci 10:1974-1994.

Card JP, Whealy ME, Robbins AK, Moore RY, Enquist LW (1991) Two $\alpha$-herpesvirus strains are transported differentially in the rodent visual system. Neuron 6:957-969.

Card JP, Whealy ME, Robbins AK, Enquist LW (1992) Pseudorabies virus envelope glycoprotein $\mathrm{gI}$ influences both neurotropism and virulence during infection of the rat visual system. J Virol 66:30323041.

Chou J, Kern ER, Whitley RJ, Roizman B (1990) Mapping of herpes simplex virus-1 neurovirulence to, 34.5 , a gene nonessential for growth in culture. Science 250:1262-1266.

del Rio-Hortega F, Penfield W (1927) Cerebral cicatrix: the reaction of neuroglia and microglia to brain wounds. Bull Johns Hopkins Hosp 41:278-303.

Dolivo M, Beretta E, Bonifas V, Foroglou C (1978) Enzymatic activity, ultrastructure and function in ganglia infected with a neurotropic virus. Brain Res 140:111-123.

Dotti CG, Simmons K (1992) Polarized sorting of viral glycoproteins to the axon and dendrites of hippocampal neurons. Cell 62:63-72.

Dubois-Dalcq M, Rentier B, Hooghe-Peters E, Haspel MV, Knobler RL, Holmes K (1982) Acute and persistent viral infections of differentiated nerve cells. Rev Inf Dis 4:999-1014.

Duffy PE (1983) Astrocytes: normal, reactive, and neoplastic. New York: Raven.

Field HJ, Hill TJ (1974) The pathogenesis of pseudorabies in mice following peripheral inoculation. J Gen Virol 23:145-157.

Fong CKY, Tenser RB, Hsiung GD, Gross PA (1973) Ultrastructural studies of the envelopment and release of guinea pig herpes-like virus in cultured cells. Virology 52:468-477.

Frei K, Malipiero UV, Leist TP, Zinkernagel RM, Schwab ME, Fontana A (1989) On the cellular source and function of interleukin-6 production in the central nervous system during experimental autoimmune encephalomyelitis. Eur J Med 164:689-694.

Gcuze HJ, Morre DJ (1991) Trans-Golgi reticulum. J Electron Microsc Tech 17:24-34.

Hopkins CR, Gibson A, Shipman M, Miller K (1990) Movement of internalized ligand-receptor complexes along a continuous endosomal reticulum. Nature 346:335-339.

Hsu SM, Raine L, Fanger H (1981) Use of avidin-biotin-peroxidase techniques: a comparison between ABC and unlabeled antibody (PAP) procedures. J Histochem Cytochem 29:577-580.

Inglesias G, Pijoan C, Molitor T (1989) Interactions of pseudorabies virus with swine alveolar macrophages. I. Virus replication. Arch Virol 104:107-115.

Jansen ASP, Ter Horst GJ, Mettenleiter TC, Loewy AD (1992) CNS cell groups projecting to the submandibular parasympathetic preganglionic neurons in the rat: a retrograde transneuronal viral cell body labeling study. Brain Res 572:253-260.

Johnson DC, Spear PG (1982) Monensin inhibits the processing of herpes simplex virus glycoproteins, their transport to the cell surface, and the egress of virions from infected cells. J Virol 43:1102-1112.

Johnson DC, Spear PG (1983) O-linked oligosaccharides are acquired by herpes simplex virus glycoproteins in the Golgi apparatus. Cell 32:987-997.

Jones F, Grose C (1988) Role of cytoplasmic vacuoles in varicellazoster virus glycoprotein trafficking and virion envelopment. J Virol 62:2701-2711.

Katz LC, Burkhalter A, Dreyer WJ (1984) Fluorescent latex micro- spheres as a retrograde neuronal marker for in vivo and in vitro studies of visual cortex. Nature 310:489-500.

Kaur C, Ling EA (1992) Activation and re-expression of surface antigen in microglia following epidural application of kainic acid in the rat brain. J Anat 180:333-342.

Kimman TG, de Wind N, Oei-Lie N, Pol JMA, Berns AJM, Gielkens ALJ (1992) Contribution of single genes within the unique short region of Aujeszky's disease virus (suid herpesvirus type 1) to virulence, pathogenesis and immunogenicity. J Gen Virol 73:243-251.

Komuro M, Tajima M, Kato K (1989) Transformation of Golgi membrane into the envelope of herpes simplex virus in rat anterior pituitary cells. Eur J Cell Biol 50:398-406.

Kristensson K, Olssen Y (1971) Retrograde axonal transport of protein. Brain Res 29:363-365.

Kristensson K, Ghetti B, Wisnicwski HM (1974) Study on the propagation of herpes simplex virus (type 2) into the brain after intraocular injection. Brain Res 69:189-201.

Kristensson K, Vahlne A, Persson LA, Lycke E (1978) Neural spread of herpes simplex virus types $\mathrm{I}$ and 2 in mice after corneal or subcutaneous (footpad) inoculation. J Ncurol Sci 35:331-340.

Kristensson K, Nennesmo I, Persson I, I.ycke E (1982) Neuron to neuron transmission of herpes simplex virus. Transport of virus from skin to brainstem nuclei. J Neurol Sci 54:149-156.

Langford LA, Coggeshall RE (1980) The use of potassium ferricyanide in neural fixation. Anat Rec 197:297-303.

LaVail MM, LaVail JH (1973) Retrograde intraaxonal transport of horseradish peroxidase in retinal protein for identification of cell bodies of origin of axons terminating within the CNS. Brain Res 58:470477.

Lee K, Bao J, Wang J, Weiming Z, Liu S, Si J, Wang Y, Zhang W, Jiang J (1987) Ultrastructural study of the morphogenesis of herpes simplex virus type 2 in organ cultured human uterine cervix and the interactions between virus and host cell. J Electron Microsc Tech 7:73-84.

Licberman AP, Iitha PM, Shin HS, Shin ML (1989) Production of tumor necrosis factor and other cytokines by astrocytes stimulated with lipopolysaccharide or a neurotropic virus. Proc Natl Acad Sci USA 86:6348-6352.

Lycke E, Kristensson K, Svennerholm B, Vahlne A, Ziegler RJ (1984) Uptake and transport of herpes simplex virus in neurites of rat dorsal root ganglia cells in culture. J Gen Virol 65:55-64.

Lycke E, Hamark B, Johansson M, Krotochwil A, Lycke J, Svennerholm B (1988) Herpes simplex virus infection of the human sensory neuron. An electron microscopy study. Arch Virol 101:87-104.

Marchand CF, Schwab M (1986) Binding, uptake and retrograde transport of herpes virus suis in sympathetic neurons. Brain Res 383:262270

Martin X, Dolivo M (1983) Neuronal and transneuronal tracing in the trigeminal system of the rat using herpes virus suis. Brain Res 273:253-276.

Massa PT, Dorrics R, ter Mculen V (1986) Viral particles induce Ia antigen expression on astrocytes. Nature 320:543-546.

Massa PT, Brinkmann R, ter Meulen V (1987a) Inducibility of Ia antigen on astrocytes by murine coronavirus JHM is rat strain dependent. J Exp Med 166:259-264.

Massa PT, ter Mculen V, Fontana A (1987b) Hypersensitivity of Ia antigen on astrocytes correlates with strain-specific susceptibility to experimental autoimmune encephalomyelitis. Proc Natl Acad Sci USA $84: 4219-4223$.

McCracken RM, Clarke JK (1971) A thin-section study of the morphogenesis of Aujeszky's disease virus in synchronously infected cell cultures. Arch Gesamte Virusforsch 34:189-201.

Mellman I, Simons K (1992) The Golgi complex: in vitro veritas? Cell 68:839-840.

Mesulam M-M (1982) Principles of horseradish peroxidase neurochemistry and their applications for tracing neural pathways-axonal transport, enzyme histochemistry and light microscopic analysis. In: Tracing neural connections with horseradish peroxidase (Mesulam M-M, ed), pp 1-151. New York: Wiley.

Milligan CE, Levitt P, Cunningham TJ (1991) Brain macrophages and microglia respond differently to lesions of the developing and adult visual system. J Comp Neurol 314:136-146.

Miselis RR, Lee BH, Enquist LW, Card JP (1991) Characterization of the visceral neuraxis by transncuronal passage of pseudorabies virus. Soc Neurosci Abstr 17:545.13. 
Miyamoto K, Morgan C (1971) Structure and development of viruses as observed in the electron microscope. XI. Entry and uncoating of herpes simplex virus. J Virol 8:910-918.

Mollenhauer HH, Morre DJ (1991) Perspectives on Golgi apparatus form and function. J Electron Microsc Tech 17:2-14.

Morahan PS (1983) Interactions of herpesviruses with mononuclear phagocytes. In: Immunobiology of herpes simplex virus infection (Roubse B, Lopez. C, eds), pp 71-89. Boca Raton, FL: CRC.

Morahan PS, Connor JR, Leary KR (1985) Viruses and the versatile macrophage. Br Med Bull 41:15-21.

Morgan C, Rose HM, Holden M, Jones EP (1959) Electron microscopic observations on the development of herpes simplex virus. J Exp Med 110:643-656.

Morgan C, Rose HM, Mednis B (1968) Electron microscopy of herpes simplex virus. I. Entry. J Virol 2:507-516.

Morre DM (1991) Role of the Golgi apparatus in cellular pathology. J Electron Microsc Tech 17:200-211.

Nadelhaft I, Vera PL, Card JP, Miselis RR (1992) Central nervous system neurons labeled following the injection of pseudorabies virus into the rat urinary bladder. Neurosci Lett 143:271-274.

Nii S, Morgan C, Rose HM (1968a) Electron microscopy of herpes simplex virus. II. Sequence of development. J Virol 2:517-533.

Nii S, Morgan C, Rose HM, Hsu KC (1968b) Electron microscopy of herpes simplex virus. IV. Studies with ferritin-conjugated antibodies. J Virol 2:1172-1184.

Norgren RB Jr, Lehman MN (1989) Retrograde transneuronal transport of herpes simplex virus in the retina after injection in the superior colliculus, hypothalamus and optic chiasm. Brain Res 479:374-378.

Norgren RB Jr, McLean JH, Bubcl HC, Wander A, Bernstein DI, Lehman MN (1992) Anterograde transport of HSV-1 and HSV-2 in the visual system. Brain Res Bull 28:393-399.

Peeters B, De Wind N, Hooisma M, Wagenaar F, Gielkens A, Moormann R (1992) Pseudorabics virus envelope glycoproteins gp 50 and gII are essential for virus penetration, but only gII is involved in membrane fusion. J Virol 66:894-905.

Pickel VM, Chan J, Milner TA (1989) Cellular substrates for interactions between neurons containing phenylethanolamine $N$-methyltransferase and GABA in the nuclei of the solitary tracts. J Comp Neurol 286:243-259.

Pol JMA, Gielkens ALJ, van Oirschot JT (1989) Comparative pathogenesis of three strains of pscudorabies virus in pigs. Microbiol Pathol 7:361-371.

Pol JMA, Quint WGV, Kok JL, Broekhuysen-Davies JM (1991a) Pseudorabies virus infections in explants of porcine nasal mucosa. Res Vet Sci 50:45-53.

Pol JMA, Wagenaar F, Gielkens A (1991b) Morphogenesis of three pscudorabies virus strains in porcine nasal mucosa. Intervirology 32 : 327-337.

Rinaman L, Miselis RR (1987) The organization of vagal innervation of rat pancreas using cholera toxin-horseradish peroxidase conjugate. J Auton Nerv Syst 21:109-125.

Rinaman L, Card JP, Schwaber JS, Miselis RR (1989) Ultrastructural demonstration of a gastric monosynaptic vagal circuit in the nucleus of the solitary tract in rat. J Neurosci 9:1985-1996.

Rinaman L, Milligan CE, Levitt P (1991) Persistence of Fluoro-gold following degeneration of labeled motoneurons is due to phagocytosis by microglia and macrophages. Neuroscience 44:765-777.

Rinaman L, Card JP, Enquist LW (1993) Spatiotemporal response of astrocytes, ramified microglia, and brain macrophages to central neuronal infection with pseudorabies virus. J Neurosci 13:685-702.

Roizman B, Sears AE (1990) Herpes simplex viruses and their replication. In: Virology (Fields BN et al., eds), pp 1795-1841. New York: Raven

Rotto-Percelay DM, Wheeler JG, Osorio FA, Platt KB, Loewy AD (1992) Transneuronal labeling of spinal interneurons and sympathetic preganglionic neurons after pseudorabies virus injections in the rat medial gastrocnemius muscle. Brain Res 574:291-306

Rouiller EM, Capt M, Dolivo M, DeRibaupierre F (1986) Tensor tympani reflex pathways studied with retrograde horseradish perox- idase and transneuronal viral tracing techniques. Neurosci Lett 72 : 247-252.

Rouiller EM, Capt M, Dolivo M, DeRibaupierre F (1989) Neuronal organization of the stapedius reflex pathways in the rat: a retrograde HRP and viral transncuronal tracing study. Brain Res 476:21-28.

Sarmiento M, Kleincrman ES (1990) Innate resistance to herpes simplex virus infection. Human lymphocyte and monocyte inhibition of viral replication. J Immunol 144:1942-1953.

Schmued LC, Fallon JH (1986) Fluoro-gold: a new fluorescent retrograde axonal tracer with numerous unique properties. Brain Res 377:147-154

Shapiro RE, Miselis RR (1985) The central organization of the vagus nerve innervating the stomach of the rat. J Comp neurol 238:473488 .

Smith JD, de Harven E (1974) Herpes simplex virus and human cytomegalovirus replication in W1-38 cells. I. Sequence of viral replication. J Virol 12:919-930.

Spear PG (1984) Glycoproteins specified by herpes simplex viruses. In: The herpesviruses, Vol 3 (Roizman B, ed), pp 31 5-356. New York: Plenum.

Stackpole CW (1969) Herpes-type virus of the frog renal adenocarcinoma. I. Virus development in tumor transplants maintained at low tempcrature. J Virol 4:75-93.

Sternberger LA (1979) The unlabeled antibody peroxidase-anti-peroxidase (PAP) method. In: Immunocytochemistry (Sternberger L, ed) pp 104-169. New York: Wiley.

Stcrnini C, De Giorgio R, Anderson K, Enquist LW, Card JP, Rinaman L (1991) Pancreatic neuronal circuits defined by transneuronal transport of pseudorabies virus. Soc Neurosci Abstr 17:545.8.

Strack AM, Loewy AD (1990) Pseudorabies virus: a highly specific transneuronal cell body marker in the sympathetic nervous system. J Neurosci 10:2139-2147.

Strack AM, Sawyer WB, Hughes JH, Platt KB, Loewy AD (1989a) A general pattern of CNS innervation of the sympathetic outflow demonstrated by transneuronal pseudorabies viral infections. Brain Res 491:156-162.

Strack AM, Sawyer WB, Platt KB, Loewy AD (1989b) CNS cell groups regulating the sympathetic outflow of the adrenal gland as revealed by transncuronal cell body labeling with pseudorabies virus. Brain Res 491:274-296.

Streit WJ, Graeber MB, Kreutzberg GW (1988) Functional plasticity of microglia. Glia 1:301-307.

Thery C, Chamak B, Mallat M (1991) Cytotoxic effect of brain macrophages on developing neurons. Eur J Neurosci 3:1 155-1164.

Ugolini G, Kuypers HGJM, Simmons A (1987) Retrograde transneuronal transfer of herpes simplex virus type 1 (HSV 1) from motoneurons. Brain Res 422:242-256.

Vahlne A, Nystrom B, Sandberg M, Hamberger A, Lycke E (1978) Attachment of herpes simplex virus to neurons and glial cells. J Gen Virol 40:359-371.

Vahlne A, Svennerholm B, Snadberg M, Hamberger A, Lycke E (1980) Differences in attachment between herpes simplex type 1 and type 2 viruses to neurons and glial cells. Infect Immunol 28:675-680.

Weinstein DL, Walker DG, Akiyama H, McGeer PL (1990) Herpes simplex virus type I infection of the CNS induces major histo-compatibility complex antigen expression on rat microglia. $J$ Neurosci Res 26:55-65.

Whealy ME, Card JP, Meade RP, Robbins AK, Enquist LW (1991) Effect of Brefeldin A on alphaherpesvirus membrane protein glycosylation and virus egress. J Virol 65:1066-1081.

Witsell AL, Schook LB (1992) Tumor necrosis factor a is an autocrine growth regulator during macrophage differentiation. Proc Natl Acad Sci IJSA 89:4754-4758

Zsak L, Sugg N, Ben-Porat T (1992) The different interactions of a gIII mutant of pseudorabies virus with several different cell types. J Gen Virol 73:821-827.

Zuckermann FA, Zsak L, Mettenleiter TC, Ben-Porat T (1990) Pseudorabies virus glycoprotein gIII is a major antigen for murine and swine virus-specific cytotoxic T lymphocytes. J Virol 64:802-812. 